\title{
La ruptura de la proximidad en una sociedad polarizada: el caso del Convento de Santa Clara en Mérida-Venezuela. 1810-1827
}

\author{
The breakdown of the proximity in a polarized society: the case of \\ the Santa Clara Convent in Mérida, Venezuela. 1810 - 1827
}

\author{
Luis Alberto Ramírez Méndez*
}

RESUMEN

A principios del siglo XIX, la sociedad hispanoamericana se polarizó escindiéndose en dos bandos antagónicos, conocidos como monárquicos y patriotas, cuyos conflictos se apreciaron significantemente en los ámbitos ideológicos e institucionales, los que a su vez, que motivaron la fractura en los lazos de proximidad. Esa situación fue vivenciada en el monasterio de Clarisas de Mérida (Venezuela), se estableció en 1651, destinado a la profesión de las mujeres privilegiadas del occidente de la actual República de Venezuela, disfrutando de respeto de sociedad y asimismo fueron depositarias de significativos montos de capital, convirtiéndose en el convento más importante del occidente de Venezuela. La incidencia de la polarización de la sociedad independentista determinó la ruptura de los lazos de proximidad en el interior del convento Clarisas emeritenses motivando la separación tanto física como ideológica de las religiosas, cuyas incidencias y efectos fueron traumáticos para las enclaustradas.

PALABRAS ClaVES: Clarisas. Polarización. Proximidad. Independencia. Monjas.

\begin{abstract}
The Breakdown of the Proximity in a Polarized Society: The Case of the Santa Clara Convent in Mérida, Venezuela. 1810 - 1827. In the early nineteenth century, the Spanish American society was polarized and split into two hostile camps, known as Royalists and Patriots, whose conflicts were appreciated significantly over the ideological and institutional areas. In turn, that led to the breaking of any bonds of proximity. This situation was experienced in the convent of Poor Clares of Merida, Venezuela; an institution that was established in 1651 for the religious profession of privileged women of the west of the present Republic of Venezuela, enjoying the respect of society and also, they were depository of significant amounts of capital, becoming the most important convent in western Venezuela. The incidence of the polarization of the independence times society determined the breakdown of close ties within the Poor Clares convent of Merida, motivating physical and ideological separation of the nuns. The implications and effects were traumatic for these cloistered women.
\end{abstract}

KEYWORDS: Clarisse. Polarization. Proximity. Independence. Nuns.

\section{Introducción}

El debate sobre las causas que condujeron a la independencia hispanoamericana ha motivado numerosas ópticas y corrientes que pretenden explicar

\footnotetext{
* Adscrito al Grupo de Investigación Geografía Histórica de las Regiones Hispanoamericanas (GHIRA) y profesor en la Maestría en Historia, Escuela de Historia. Facultad del Humanidades y Educación. Universidad de los Andes. (Mérida-Venezuela).
} 
los motivos que originaron la ruptura del nexo colonial. Con ese propósito, a finales del siglo XIX, los investigadores de tendencia católica e hispanista minimizaron la influencia del liberalismo europeo considerando que las aspiraciones libertarias de los criollos tenían profundas raíces en la propia tradición española. Concretamente, J aime Eyzaguirre $(1957,1966)$, ha afirmado que al ser derrocada la monarquía española por Napoleón en 1808, la soberanía retornó a su fuente originaria, porque según la tradición jurídica filosófica, el poder de los reyes había sido cimentado sobre el pueblo. La premisa hacía innecesaria la indagación en influencias externas alegando que [...] no hacía falta, pues, que se buscaran fuera del acervo hispánico los conceptos de libertad. (EYZAGUIRRE, (1957, p. 119).

Asimismo, los ibéricos han desestimado los efectos de la carencia del libre comercio en las colonias hispanas, argumentando que las reformas borbónicas ya habían satisfecho esta aspiración (FERNÁNDEZ ALMAGRO, 1944; DELGADO MARTÍN, 1949. ENCISO RECIO, 1967). Además, los hispanistas, rechazaron que el conflicto se originara por el monopolio de los altos cargos públicos en manos de los peninsulares en detrimento de las justas aspiraciones de los criollos. Por el contrario, otros estudiosos, destacan que el epicentro de la disputa fue la creciente antipatía entre criollos e ibéricos (CARRERA DAMAS, 1983), o consideran que la revolución de 1810 fue un hecho accidental desencadenado por la invasión napoleónica a España. Por su parte, los historiadores liberales han señalado como motivo principal del movimiento emancipador a la influencia de los teóricos de la Revolución Francesa, magnificando el papel de la ideología liberal de finales del siglo XVIII y enfatizan el impacto del despotismo político y religioso en España.

Para a despecho de los enunciados investigadores, ninguna de las tesis expuestas ha logrado proporcionar una visión totalizadora del proceso que originó la independencia. La disparidad de las posiciones sostenidas por tan variados enfoques ha reducido la discusión a la sola expresión de opiniones unilaterales, confundiendo las causas de estructura con las de carácter coyuntural, los factores objetivos con los subjetivos, las causas esenciales con las aparentes, haciendo abstracción de una parte en detrimento de la totalidad y unicidad histórica.

Otra óptica de los estudios, en una aplicación simplista del marxismo, practicada a menudo por los analistas de tendencia economicista, ha conducido a sostener que la causa esencial de la revolución independentista fue la contradicción entre el desarrollo de las fuerzas productivas y las relaciones de producción. Esta contradicción, efectivamente fue determinante en las grandes revoluciones que provocaron el advenimiento de nuevas sociedades, modos de producción y Estados, 
como sucedió con la revolución francesa, las revoluciones democráticas burguesas europeas del siglo XIX, las revoluciones rusa y china, entre otras.

Pero a diferencia de los enunciados conflictos sociales, la independencia política Hispanoamericana no constituyó una superación dialéctica de la contradicción entre el desarrollo de las fuerzas productivas y las relaciones sociales de producción en el Nuevo Mundo. Por el contrario, durante la colonia, ni siquiera con las reformas borbónicas, no hubo un salto cualitativo en el desarrollo de las fuerzas productivas, condicionadas y deformadas por la metrópoli, ni tampoco se experimentaron transformaciones significativas en los sistemas de producción. Por el contrario, después de la ruptura del nexo colonial permanecieron inalterables las relaciones de propiedad, dominadas por los terratenientes, mineros y comerciantes. Los autores que pretendieron explicar el proceso de la independencia a través de esa contradicción estarían obligados, por lo menos, teóricamente, a demostrar que la revolución independentista fue una revolución social (QUINTERO, 2011), partera de un nuevo modo de producción, libre de las trabas impuestas por las relaciones de propiedad generadas por la existencia de una supuesta burguesía criolla. En este caso, dicha revolución social habría sido una revolución democrático-burguesa. Pero resulta que no fue una revolución social sino una revolución política separatista, que no transformó la estructura económica y social de la colonia. En ese sentido, es indudable que la revolución independentista cambió las formas de gobierno, más no las relaciones de propiedad ni las de producción (VITALE, 2011, p. 4).

A pesar de las señaladas e innegables diferencias en las tesis de los expresados estudios y ópticas, existe consenso en los autores que intentan explicar el origen del conflicto independista, en la omnipresencia del componente ideológico ${ }^{2}$, bien fuera en desde el punto de vista filosófico, político y económico como causal importante en el proceso de independencia hispanoamericana (FISHER; KUETHE; MCFARLANE, 1990; LYNCH, 1976). Ciertamente, y de acuerdo a los planeamientos teóricos y los hechos consumados, se enfatiza el aspecto político como trascendental, porque a través del mismo, se opusieron las ideas monárquicas absolutistas y

\footnotetext{
2 [...] Esa es, pues, la agitada y expectante Hispanoamérica contemporánea de la ilustración europea. Un mundo que ha despertado y ha echado a andar por sus propios medios, en busca de su destino histórico, y al que el Enciclopedismo y el iluminismo aportan - por acción o por reacción - motivaciones y contrastes. Un mundo que adquiere personalidad histórica a partir de sí mismo y no, como equivocadamente pretenden demostrarnos, a partir de las influencias foráneas. Con todo lo importante que fue su influencia, las ideas de la ilustración no crearon el espíritu de la insurgencia hispanoamericana. Cuando más, lo estimularon; con sus provocaciones y sugerencias, fueron el catalizador que aceleró la reacción anticolonial que condujo a la independencia...(NUÑEZ, 1989, p. 32).
} 
populistas $^{3}$. De acuerdo a esas visiones, la tesis del absolutismo, sostiene que el poder del Estado se concentraba en un sólo sujeto, representado por un emperador, rey, dictador o jefe de Estado. Por el contrario en el populismo, el poder político lo detenta el pueblo y lo ejerce a través de sus representantes. Esas precisiones, tan elementales, son necesarias porque se advierte que algunos historiadores parecen simplificar el conflicto ideológico y reducirlo a una feroz oposición entre diferentes actores y/o tendencias económicas y sociales, sin tener clara conciencia que la dicotomía ideológica tuvo ramificaciones muy dispares entre sí (RIVERA DE VENTOSA, 1990, p. 35), con profundas implicaciones en la mentalidad de los americanos.

De ese modo, se evidencia que durante las dos primeras décadas del siglo XIX, tuvo lugar en Hispanoamérica un doble conflicto: uno en el campo de las ideas y otro en el interior de las instituciones. Como resultado de ese enfrentamiento, la pugna independentista fracturó profundamente a la sociedad hispanoamericana, generando la hostilidad entre dos bandos conocidos en la historiografía tradicional como monárquicos o realistas y patriotas, los que han sido erróneamente contextualizados por los estudiosos como sectores monolíticos, agrupados e identificados en diferentes espacios sociales, económicos y políticos determinando con esa confrontación que aquella colectividad fuera extremadamente polarizada (CARRERA DAMAS, 1983, p. 1720; FIGUERA, 1960, p. 324-397). De acuerdo a lo expuesto, la polarización es entendida como el resultado de la desigualdad extrema en las ideologías de diferentes grupos sociales antagónicos, concebidas como sistemas de actitudes, valores, representaciones y creencias que buscan justificar una situación política, social y económica, afrontándose entre sí los contendientes, mediante la constante contradicción (BARRIGA et al., 1998, p. 30); generando la diferenciación, división y segregación 4 .

El fenómeno de la polarización en la sociedad hispanoamericana durante las primeras décadas del siglo XIX, no ha sido estudiado, especialmente en sus consecuencias inmediatas como lo fue la disolución de los lazos de proximidad

3 [...] Esta rebelión anticolonial formó parte de un proceso mundial de ruptura con el "antiguo régimen", expresado en el triunfo de la burguesía industrial sobre la monarquía feudal en Francia y el inicio de la Independencia de los Estados Unidos. Un mundo que no sólo había superado la fase de transición del feudalismo al capitalismo, sino que también inauguraba un nuevo ciclo histórico en el campo del pensamiento y la cultura. Rebasada la concepción teológica, en el plano de la filosofía hubo un cambio significativo entre el pensamiento aún creyente de un Descartes y las ideas radicales de Rousseau, Voltaire y, en general, del Iluminismo europeo, facilitando el avance de la ciencia y liberándola de las amarras escolásticas... (VITALE, 2011, p. 2).

4 [...] Uno de los mitos populares de hoy en día es que nos hemos convertido en una sociedad más polarizada. Se dice que cada vez estamos más divididos por la política (liberales frente a conservadores), los valores sociales (tradicionales frente a modernos), la religión (fundamentalistas frente a todos los demás), las razas, las etnias... (SAMUELSON, 2003). 
entendida como la organización simbólica de la convivencia a través del imaginario colectivo, expresado en y a través de los discursos hegemónicos que clasifican a los seres humanos en unas categorías u otras y que fijan las formas de relacionarse y articularse entre sí. En estricto sentido, la proximidad se origina en la identificación del Yo, y su diferenciación del Otro $^{5}$, con quien mantiene una relación de alter ego, que no puede ser comprendida en su profundidad, en términos de conocimiento, pues el Yo imposibilita la relación con el Otro cuando no se efectúa directamente y cara a cara. De esa forma, la proximidad es sólo comprensible como apertura del Yo a la comunicación con el Otro, sin que ninguna otra manifestación pueda suplir tal vinculación (MORENO MÁRQUEZ, 2011, p. 43-44). Por lo tanto, la autoidentificación del Yo o Nosotros y su diferenciación del Otro o Vosotros, genera la admisión de las características comunes y aceptadas, y por el contrario el rechazo a aquellas: disímiles, desconocidas o inadmisibles. De ese modo, la ruptura de la proximidad se produce en una sociedad polarizada debido al distanciamiento de la relación cara a cara, a la disociación de valores, aptitudes, representaciones y creencias comprensivos en las ideologías profesadas en los grupos contendientes entre sí, lo cual se traduce en el debilitamiento y quiebra de vínculos tantos familiares como societales entre los miembros de instituciones, cuyos actores, se escinden enfrentándose entre sí.

En la sociedad colonial hispanoamericana, el conflicto ideológico fue causa determinante de la polarización y su inmediata secuela la ruptura de la proximidad se vivenció entre los variados sectores y grupos de la colectividad, los cuales pueden ser visualizados a través de los numerosos conflictos (GINER, 2008; MURILLO, 2008) pre-independetistas, en cuyas contingencias se aprecian las tensiones propias entre personas y grupos opuestos debido a su identificación con valores creencias e intereses antagónicos, los que demuestran la separación que progresivamente se profundizó hasta llegar al conflicto independentista, en la búsqueda de la compensación de intereses que se consideraban lesionados, pero que finalmente sólo se concretaron en la ruptura de los lazos políticos con España.

En los diversos estratos sociales, fueron diferentes los efectos de aquel conflicto, fundamentalmente en sus niveles de aceptación y rechazo, esencialmente al interior del sector eclesiástico Hispanoamericano. Desde el punto de vista de la percepción de la soberanía de derecho divino en las jerarquías superiores clericales

\footnotetext{
${ }^{5}$ [...] En nuestra opinión, el nos-otros que hace violencia al sentido de corrección lingüística, el nosotros con guión y con la posibilidad de hacer gravitar la carga identificatoria sobre el uno o el otro de sus componentes, convirtiéndolos alternativamente en sujeto y contrasujeto es más fiel a lo significado, porque se trata, en todo caso y en el seno de un sujeto divido del; del un desplazamiento del centro de su identidad que tiende a subjetivar la totalidad subjetiva a la óptica de sus partes [...]. (BRICEÑO GUERRERO, 1980, p. 15).
} 
siempre se concibió como producto de una extremada veneración hacia el Rey de España. En ese sentido, Ballesteros y Berreta (1932, p. 710) afirma que los prelados de América eran acérrimos realistas. Pero a diferencia de los anteriores, William Taylor (1999) expone múltiples testimonios que certifican la actuación del clero inferior y las órdenes religiosas, en especial los misioneros, quienes también manifestaron en general una profunda sumisión a la realeza ${ }^{6}$. Pero, ¿fue idéntica la actitud de las altas jerarquías eclesiásticas y la del clero inferior que vivía en estrecha proximidad con el pueblo? Es difícil, en verdad dilucidar esa interrogante, pero a grosso modo, se atestigua que el alto clero fundaba su veneración a la persona del rey, en el supuesto del derecho divino, en el cual la voluntad de Dios era inherente a éste, tal y como lo formuló Bossuet, mientras que el clero popular se sentía veneración a su rey porque, como mandatario del pueblo, representaba la personificación de una gran misión histórica, considerando al monarca como un agente primario del sentido religioso en toda la hispanidad. Del mismo modo, los historiadores afirman que tanto los virreyes como la mayoría de los funcionarios de Indias habían nacido en España, circunstancia que fue muy desagradable a los criollos, y por ello se sintieron inclinados al separatismo7. Esa situación, que fue importante en la génesis de los movimientos emancipadores, se enfatiza para explicar como los funcionarios, venidos de España, estuvieran lastrados por la persistente ideología del absolutismo. Por la misma razón, también es comprensible que los clérigos, estuvieran orientados hacia el absolutismo sacro. Esta corriente, parece haber sido especialmente cultivada por aquellos prelados que se trasladaban a América, después de ser consagrados como obispos (SILVA MORENO, 2008, p. 22-23). Por ello, se explica que los primados fueran en general, adversos a los movimientos independentistas y que difundieran una devota sumisión al rey (RIVERA DE VENTOSA, 1990, p. 37), aptitud que también fue asumida por el clero formado en los colegios seminarios del Nuevo Mundo.

A diferencia del clero, institución rectora en Hispanoamérica, cuya actuación ha sido estudiada exhaustivamente durante el conflicto independentista, resaltan lo

${ }^{6}$ Clasifica a los curas párrocos en la guerra de independencia en presuntos insurgentes y presuntos realistas.

7 [...] La emergencia de la clase criolla también tuvo profundos efectos en el ámbito de la política. Puesto que los criollos eran «españoles americanos» y descendían en su mayor parte de los conquistadores y colonizadores de estas tierras, reclamaban para sí un papel preponderante en la administración colonial, que en la práctica estaba en manos de un grupo de burócratas venidos de la península, que tenían como únicos objetivos mantener la sujeción de estos territorios a la metrópoli y obtener los mayores ingresos posibles para la corona. Fue así como en las colonias españolas de América llegó a constituirse un «poder dual», entre una «clase dominante a medias» - la criolla que controlaba los medios de producción fundamentales y los más activos circuitos económicos, y una casta burocrática que actuaba como clase sin serlo, pero que detentaba el poder político en representación de la clase dominante metropolitana: la de los «chapetones» o «gachupines» [...]. (NUÑEZ, 1989, p. 23). 
superficial y descriptivo de las investigaciones que indagan el rol desempeñado por las mujeres durante el conflicto independentista, las que la historiografía tradicional les ha prestado atención, sólo cuando sus actuaciones han sido calificadas como heroicas ${ }^{8}$, casi viriles, especialmente cuando actuaron como parte de la resistencia armada o sus auxiliares $^{9}$. Esa visión sesgada del rol femenino, se justifica debido a la tradicional exclusión de las mujeres de los ámbitos de ejercicio de poder, lo que implica, en primer lugar, su inhibición en la utilización de la violencia para acceder a esos cargos, ya que históricamente el uso de métodos violentos ha sido uno de los canales más importantes de acceso al poder. Por ello, considerando que la violencia siempre es un ejercicio de poder, el hecho de que las mujeres han permanecido ajenas a los escenarios desde donde el dominio se ha ejecutado, también ha limitado las posibilidades de las mismas para actuar de forma violenta.

A pesar de las anteriores consideraciones, las secuelas de los conflictos armados afectan a todo el conjunto de las colectividades que los padecen. Particularmente, en la sociedad colonial, con estructuras predominantemente patriarcales, y debido a la extremada diferenciación en los roles que desempeñaban hombres y mujeres o su capacidad de acceder a determinados recursos, condicionaron la manera en que los conflictos armados afectaron a unos y otras. Ciertamente, debido a que la mayoría de los combatientes fueron hombres, el efecto directo de los enfrentamientos armados, en términos de pérdida de vidas humanas y heridos de guerra recayó principalmente sobre los de su género. Sin embargo, las consecuencias indirectas de estos enfrentamientos armados -que en ocasiones se convirtieron en directas puesto que se trataron de estrategias de guerra deliberadas por parte de los propios combatientes ${ }^{10}$ - tuvieron como principales receptoras a las mujeres (VILLELLAS ARIÑO, 2006, p. 7).

8 CHERPAK (1978); BREWSTER (2006); DAVIES; BREWSTER y OWEN (2006); FERNÁNDEZ LIZARDI (1985, p. 474-478); LEAL (1949); ARROM (1988); KENTNER (1975); FEBRES CORDERO (1983, p. 72-75); FEBRES CORDERO (1983, p. 86-90).

9 En ese sentido Concepción Baldos Ciria afirma que con [...] el objetivo de rescatar las estrategias de las que se sirvieron las mujeres latinoamericanas para contribuir a la causa independentista, superando y rebasando los controles y límites impuestos por el sistema patriarcal dominante, teniendo en cuenta condicionantes como la raza y la clase social, además del que nos ocupa en este trabajo: el género. Más que la exaltación heroica de estas mujeres, a los estudios de género les interesa analizar y tratar la incidencia y la repercusión que estos acontecimientos han podido tener en la historia de las mujeres en Latinoamérica, después de doscientos años de independencia., sobre todo en los que afecta a su incursión y participación en la esfera pública y, por ende, en la política [...]. (BALDOS CIRIA, 2009, p. 1).

10 [...] Existe numerosa información sobre casos de mujeres que durante la guerra de la independencia se les encausó por infidentes, a quienes se les juzgó al ser encarceladas ejecutadas, deportadas y privadas de sus propiedades por actividades rebeldes como seducción de la tropa, contrabando de mensajes y armas, espionaje. Conspiración, abastecimiento económico, por ser soldadas, guiar a los rebeldes por los caminos, atender a los enfermos en los improvisados hospitales, llevar agua y enterrar a los difuntos [...]. (GARRIDO ASPERÓ, p. 170). 
Entre esas consecuencias indirectas, están las que se derivaron de la destrucción de los campos de cultivo o la restricción en el acceso a determinados bienes y servicios, infraestructura y alimentación. Ello, se evidencia debido a que durante el transcurso de los conflictos armados, las mujeres frecuentemente se convirtieron en las abastecedoras de las comunidades y familias y asumieron la satisfacción de las necesidades básicas de las personas que estaban a su cargo.

Del mismo modo, la tradición historiográfica ha excluido otros tipos de participación femenina en el conflicto emancipador, aparte de la ya expresada que efectuaron en los campos bélicos, debido a que las mujeres tradicionalmente desplegaban sus actividades cotidianas en el interior de los recitos domésticos, lo cual ha determinado como lo acertadamente la señala Evelyn Cherpak que las damas fueran abandonadas por los combatientes, que en numerosas ocasiones fallecieron, dejando viudas, madres, hijas huérfanas y hermanas desamparadas que sufrieron no sólo las ausencias de sus hombres sino las carencias que derivaron de la esas separaciones forzosas. Pero, aún más evidente ha sido el desinterés por historiar las actuaciones de las mujeres recluidas en los numerosos conventos de clausura de las órdenes mendicantes establecidas en América durante el conflicto independentista, lo cual hace relevante y pertinente la indagación para explorar la ideología política, mentalidad y proximidad de las conventuales durante esas dos primeras décadas del siglo XIX.

En ese sentido, el presente trabajo se centra en el estudio del conflicto por la independencia y sus incidencias en el interior del Monasterio de San J uan Bautista de la orden de Santa Clara en Mérida - Venezuela, cuyas monjas se escindieron y participaron en los bandos ideológicos contendientes durante la guerra y los efectos que aquella fractura tuvo en la institución religiosa monástica. Con tal efecto, es preciso acotar que el monasterio de Clarisas fue establecido en 1651, y durante 150 años, las monjas, descendientes de miembros connotados de la elites del occidente de la actual república de Venezuela habían disfrutado del respeto, consideración y de los beneficios del capital acumulado a lo largo de la centuria y media de la existencia de la institución, producto de las dotes que aportaron las monjas que habían profesado en el cenobio. Esa importante función financiera las hizo despostarías tanto del poder económico, como del prestigio social que gozaban el monasterio más importante del occidente de Venezuela. La investigación se asienta sobre la revisión bibliográfica y especialmente en las fuentes documentales inéditas que reposan en el Archivo Arquidiocesano de Mérida (AAM), esencialmente en la sección 54, Religiosas, sobre el expediente levantado sobre el traslado de monjas Clarisas de Mérida a Maracaibo y sobre los poderes y cartas que 
existen al respecto en el Archivo General del Estado Mérida. Se procesó la información y se presentan los resultados.

\section{El Espacio Geográfico e Histórico}

A principios del siglo XVI, la sucesiva expansión de los conquistadores hacia el nororiente de la Nueva Granada, les situaría en Tunja en 153811, una década más tarde, sería fundada Pamplona en 1548 (PAVÓN VILLAMIZAR, 1999, p. 20-24. ACOSTA MOHALEM, 1999, p. 17-20), pero la construcción de espacio jurídico político del Nuevo Reino de Granada, no se detuvo allí, sino que avanzó hasta el extremo nororiental desde Pamplona y culminó con la ilegitima fundación de Mérida en 1558², asentada sobre una amena y extensa meseta que disfruta de un agradable clima, el cual fue excepcionalmente descrito por J osep Gumilla, al explicar que era la ciudad donde se percibían los climas característicos de las cuatro estaciones, en todos los días del año, circundada por cinco ríos, los que sonoramente riegan su fértil territorio y con la impresionante vista a su parte oriental de cinco cumbres nevadas.

El establecimiento de la ciudad de los cinco picos nevados constituyó uno de los más importantes hitos en el avance de la expansión ibérica, en el Nuevo Reino de Granada, y al momento de su instauración fue sufragánea del Corregimiento de Tunja, a partir del cual tuvo un azaroso tránsito hasta asumir la capitalidad de la Provincia del Espíritu Santo en 1623, convirtiéndose en el centro de un vasto territorio que se expandía sobre gran parte del occidente de la actual república de Venezuela (RAMIREZ MENDEZ, 2011, p. 29-45) (Véase Mapa 1). En su devenir histórico la ciudad de los cinco águilas blancas experimentó un dilatado periodo de expansión económica que se extendió desde la segunda mitad del siglo XVI hasta mediados del siglo XVII, durante el cual se desarrollaron las haciendas productoras de cacao en el pie de monte andino lacustre y las de tabaco en las planicies barinesas, permitiéndole acumular una cuantiosa y significativa riqueza ${ }^{13}$.

${ }^{11}$ La fundación sucesiva de Vélez, Tunja, Tocaima y Pamplona alcanzaron los últimos confines de la influencia chibcha. La llegada de los oidores de la Audiencia marca un término convencional a la conquista. En realidad a partir de entonces crece el número de gentes deseosas de entrar a saco en nuevos territorios. Una vez que la paz se reestableció en el Perú (1548) el Nuevo Reino se vio asediado por una oleada de aventureros que intentaban atravesarlo [...]. (COLMENARES, 1978, p. 24-25).

12 Sobre el proceso fundacional de Mérida existen numerosas publicaciones desde los cronistas hasta recientes y concienzudos estudios entre otros: AGUADO (1963); SIMÓN (1983); RAMÍREZ MÉNDEZ (1994, p. 489-513); PICÓN PARRA (1988, p. 15-98); RAMÍREZ MÉNDEZ (2010); SAMUDIO (2002).

13 En el informe levantado por don Cristóbal Gámez y Costilla se refiere [...]. En lo que toca a Gibraltar eran tantas las hasiendas con tan buenas quadrillas de esclavos, que sólo de esto le benían más de cien mil pesos en un año..AGEM. Documentos históricos de la Gobernación de 
Durante ese período, la élite merideña tuvo la expresa determinación en reservarse los espacios socialmente notorios, especialmente el político, representado por el cabildo (SAMUDIO, 1999, p. 147-170) y el clero, dividido en dos ramas, el regular y secular, cuyas dignidades fueron ejercidas por el vicario, párrocos y los monjes agrupados en las diferentes órdenes que establecieron claustros en la misma ${ }^{14}$. La presencia del clero regular en Mérida es simultánea a la fundación de la ciudad, cuya primera manifestación fue la instauración del convento de los dominicos, bajo la advocación de San Vicente de Ferrer en 1563 (RAMÍREZ MÉNDEZ, 1994, p. 495).

\section{Mapa 1- Gobernación de Mérida (1623-1676)}

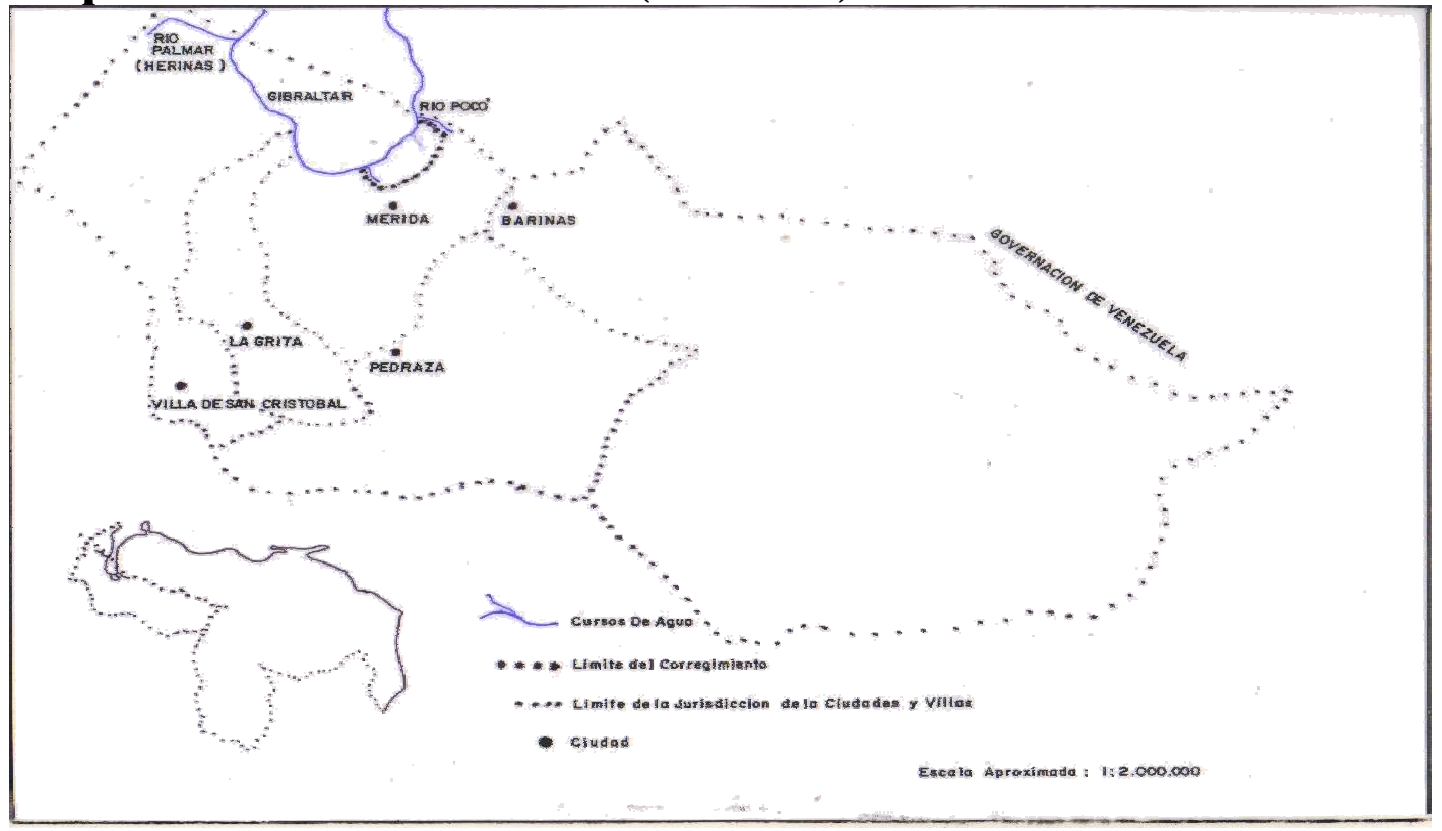

Fuente: Ramírez Méndez (2007, p. 3).

A éste le siguió el monasterio de San Juan Evangelista de la Orden de San Agustín, fundado en 1592 (CAMPO DEL POZO, 1968, p. 23), a los que acompañó el Colegio San Francisco Xavier de la Compañía de J esús en 162815; se concluyó el ciclo de las órdenes masculinas con el Convento de Nuestra Señora del Pilar de Zaragoza de la Orden de San Francisco en 1657 (SAMUDIO, 2007). En 1651, tuvo lugar la fundación del convento de San J uan Bautista de la Orden de Santa Clara, la que sería en espacio

Mérida 1704-1705-1711. Expediente promovido por el procurador don Cristóbal de Gámez y Costilla ante el cabildo solicitando esta se inhibiese de satisfacer los salarios impuestos. Testimonio de las autoridades eclesiásticas. Mérida, 24 de febrero de 1711. f. 12v.

${ }^{14} \mathrm{El}$ ser sacerdote o monja fue un privilegio para la sociedad de la época y uno de los méritos que orgullosamente se exhibía, cuando se consideraba necesario demostrar la limpieza de sangre e hidalguía. (SAMUDIO, 1996, p. 86-87).

15 Sobre los jesuitas en Mérida, existe una extensa bibliografía. (LEAL (1965); AGUIRRE ELORRIAGA (1941); CHACÓN (1980); SAMUDIO (1985); FAJARDO; SAMUDIO; BRICEÑO JÁUREGUI (1996). 
social de las mujeres de la elite emeritense, para lo cual se destinaron cuantiosos recursos, tanto en la construcción de su edificio como en las dotes que se entregaron a las monjas que profesaron en el cenobio (RAMÍREZ MÉNDEZ, 2005).

Aquel extraordinario periodo de prosperidad y bonanza fue seguido por una severa crisis, originada por los incesantes ataques de los piratas al puerto emeritense de San Antonio de Gibraltar ${ }^{16}$ y los temibles sismos ocurridos a partir de 8 de diciembre de 1673, cuyas replicas se sintieron por los sucesivos tres meses hasta marzo de 1674, especialmente en las llanuras del pie de monte andino lacustre ${ }^{17}$, donde ocasionaron derrumbes en las cabeceras de las torrenteras, las cuales al precipitarse sobre aquellas explanadas originaron un aterrador deslave, arruinando las prósperas haciendas cacaoteras.

Esas dramáticas circunstancias trastocaron su prosperidad y destruyeron gran parte de la infraestructura agraria ${ }^{18}$, motivando el descenso de la población, y determinó el traslado de la capital de la provincia desde Mérida a Maracaibo ${ }^{19}$, lo cual inició desde entonces un fuerte enfrentamiento entre ambas ciudades, la primera neogranadina de origen y la segunda venezolana por la capitalidad de la provincia lo que se tradujo en una incesante lucha de los emeritenses por liberarse de la dependencia de los marabinos.

Los efectos de aquellos terribles y devastadores eventos, se extendieron hasta la primera mitad del siglo XVIII, centuria en que los emeritenses lucharon denodadamente por reedificar la ciudad, erigir nuevamente sus residencias, los templos y reestablecer la destruida estructura agraria, la que nuevamente proporcionó beneficios a sus habitantes. Durante esas dos centurias, los merideños mantuvieron estrechos vínculos tanto de parentesco como sociales y económicos con otras importantes familias y centros urbanos de la Nueva Granada como Tunja, El Socorro y Pamplona, interconectados por el camino que se expandía hasta Santa Fe de Bogotá, la cual fue elevada definitivamente al rango de capital virreinal en 1747.

${ }^{16}$ AGNB. Historia Civil. t. 16. Autos sobre el socorro de la ciudad de San Antonio de Gibraltar por averla invadido el inglés [sic] y muerte del gobernador. 1666. Informe de los alcaldes ordinarios de Mérida Andrés Henríquez de Padilla y Alonso Ruiz Valero. Mérida, 18 de julio de 1666. f. 887r.

17 [...] luego en el año de setenta y quatro... con los horrorosos temblores que se padecieron con aniquilación de edificios y templos y casas de esta ciudad que oy están desiertas e inhabitables... AGI. Santo Domingo. Legajo 202. Informe del procurador general de Mérida José García de Ambas. Mérida, 20 de abril de 1688. f. $47 \mathrm{v}$.

18 [...] y habiéndose removido y desmoronado los montes y echo represas... AGI. Santo Domingo. Legajo 202. Informe del procurador general de Mérida José García de Ambas. Mérida, 20 de abril de 1688. f. 47v.

19 AGNB. Poblaciones T. X. Real Cédula que ordena la separación de Maracaibo de la Provincia de Venezuela y su anexión a la Provincia de Mérida. Madrid, 31 de diciembre de 1676. ff. 334r-335r. (ARMAS CHITY, 1957, p. 48-49). 
Durante la segunda mitad de aquella centuria, el virreinato, era un conglomerado de regiones, separadas por montañas, selvas, llanuras y ríos, que permanecían semi-aisladas debido a su deficiente red de comunicaciones. Los expresados centros urbanos concentraban en sus jurisdicciones importantes y significativas actividades económicos y concentraban en sus distritos alrededor de 485.000 habitantes, aproximadamente el $60 \%$ de la totalidad de la población de la Nueva Granada (LYNCH, 1976, p. 256). Cada comarca era más o menos autosuficiente en su producción agrícola, pero también en algunas áreas se desarrollaban otras actividades económicas como la manufactura, ganadería, el laboreo en las minas de plata y oro. Ulteriormente, en 1777, y como producto de la reorganización territorial iniciada por los Borbones, tanto Mérida como Maracaibo fueron seccionadas del Virreinato de la Nueva Granada y fueron agregadas a la Capitanía General de Venezuela (MORON, 1977, p. 77).

Por aquella fecha ${ }^{20}$, la Corona española, procedió a erigir un nuevo obispado, que se extendía por un vasto sector del occidente de la actual República de Venezuela pues incluía a Coro, Maracaibo, Trujillo, La Grita, Barinas San Fernando de Apure y parte del nororiente neogranadino con las vicarías de Cúcuta y Pamplona, la sede de la catedral y el obispado fue fijada en Mérida, a despecho de los marabinos quienes aspiraban que fuera asentada en Maracaibo, lo cual avivó aún más tensiones entre los naturales de ambas ciudades por la primacía de la capitalidad iniciada en el siglo anterior.

La erección del obispado en la ciudad de las cinco águilas blancas, le proporcionó en primer término la preponderancia eclesiástica, sobre aquel extenso territorio con la radicación del cabildo catedral, lo cual representaba que el alto clero tendría su residencia en la misma, al mismo tiempo que se beneficiaba de las rentas decimales que se cuantificaron en 30.000 pesos anuales, en 1806 (MARTÍNEZ REYES, 1980, p. 90).

Además, aquella disputa se acentuó, cuando el primer obispo de la diócesis, fray J uan Ramos de Lora fundó el Colegio Seminario de San Buenaventura, cuya sede fue la ciudad de los picos nevados, centro educativo que los marabinos también ambicionaban se erigiera en su ciudad y que se convirtió en el germen de la actual

${ }^{20}$ La fecha de bula corresponde al 16 de febrero de 1778, pero muchos historiadores, cometieron el error de tomar la misma como tal y como aparece, pero obviaron que durante aquel periodo se computaban los años eclesiásticos de acuerdo a lo dispuesto por el papa Eugenio IV en 1.445, quien determinó que en las bulas se tuvieran como día primero del año al día de la Encarnación del Señor o sea el 25 de marzo, práctica que duró hasta 1908, fecha en la cual Pío X dispuso que se siguiera el computo civil. En las bulas anteriores a ese año, los días comprendidos desde el 10 de enero al 25 de marzo se consideran inclusos en el año civil anterior; por tanto el 16 de febrero de la Encarnación del Señor 1777, corresponde al 16 de febrero de 1778. (GARCÍA, 1958, p. 314-369). 
ilustre Universidad de Los Andes (SAMUDIO, 2003). De esa forma, Mérida congregaba en su seno la elite intelectual y eclesiástica del occidente de la actual Venezuela, y parte del nororiente de Colombia, colocando a su disposición cuantiosos ingresos económicos.

\section{El Conflicto por la Independencia en Mérida}

El inicio de los conflictos ideológicos en Mérida, tuvo su génesis con la expulsión de los jesuitas en 1769, la orden de Carlos III, se cumplió en la ciudad de las nieves eternas con expatriación de los ignacianos y el cierre del colegio el de San Francisco J avier, el primero establecido en Venezuela por aquellos religiosos en 1628, con lo cual la ciudad fue privada de su centro de estudios de gramática y teología (CHACÓN, 1980). Hasta el presente, se carecen de monografías que aborden la influencia que tuvieron los padres de la orden de Loyola sobre el pensamiento de los criollos emeritenses, especialmente con respecto a las ideas neoliberales que estaban en boga en Europa. A pesar de ello, variados autores coinciden en afirmar que la trascendencia de la enseñanza en aquellos colegios fue significativa en el desarrollo de las ideas independentistas ${ }^{21}$. La expulsión de los jesuitas fue la primera medida de la política reformadora de los Borbones que tocó profundamente la alianza entre el trono y el altar, sellada por el patronato regio en el siglo XVI y fue recibida hasta con cierto júbilo por los miembros de otras órdenes religiosas, que consideraron positiva aquella disposición ${ }^{22}$. Esas instrucciones, fueron el inició de las providencias secularizadoras del Estado español de Indias, las que fueron continuadas con las órdenes desamortizadoras del capital eclesiástico impuestas en la península a finales del siglo XVIII, y en América durante las primeras décadas del siglo XIX (LAVRIN, 1993).

Sin embargo, aquellas normas, no tuvieron una repercusión que ocasionara conflictos sociales, pero al avanzar la segunda mitad del siglo XVIII, Mérida fue estremecida por la rebelión comunera, que tuvo como motivo la imposición de nuevos impuestos, que se inició en el Socorro, movilizando a más de 6.000 hombres armados

21 [...] La medida obedecía sin duda a un frío cálculo político. Al expulsar a los jesuitas y apoderarse de sus recursos y propiedades, la corona liquidaba el poder bancario que financiaba a los propietarios y empresaria criollos, debilitaba la capacidad económica de estos, obtenía grandes riquezas y eliminaba una parte sustancial del poder latifundista en sí mismo. A su vez, en el plano político, privaba al criollismo de su élite intelectual - la mayor parte de los jesuitas extrañados era de origen criollo y provenía de las grandes familias locales, al mismo tiempo que rompía en gran medida el vínculo social establecido entre la Iglesia y la clase criolla... (NUÑ̃Z, 1989, p. 26).

22 [...] Si bien las demás órdenes y gran parte de la jerarquía eclesiástica aplaudieron la expulsión de la Societas Jesu por razones de rivalidad, pronto el clero se dio cuenta de que el ataque antijesuítica no fue un caso singular, sino que el rol de toda la Iglesia se estaba viendo cuestionado por parte de los reformadores borbónicos...(SCHMIDT, 2011) 
que se bifurcaron en dos direcciones ${ }^{23}$. La conflagración se extendió hacia Simácota, San Gil, Girón, Oiba, Gámeza, Tunja, Pamplona, Cúcuta, acaudillados por J osé Antonio Galán y Francisco J osé Berbeo. Una parte de aquel movimiento se dirigió hacia Santa Fe de Bogotá y otra hacia Mérida, donde depusieron las autoridades capitulares y las sustituyeron por el gobierno del común, entendiendo por esto la supresión del gobierno de los nobles blancos criollos pertenecientes a las calidades superiores por los miembros de las calidades medias de la sociedad.

Ello, no sólo ocurrió en Mérida, sino también en La Grita y la Villa de San Cristóbal, motivando la fractura y el distanciamiento en las relaciones de proximidad entre diferentes grupos sociales y con esas actuaciones afectaron especialmente a los hacendados, los que en ocasiones eran eclesiásticos. La rebelión finalizó con la firma de las capitulaciones de Zipaquirá, y su posterior desconocimiento. Al mismo tiempo, los principales líderes fueron enjuiciados y ejecutados, otros fueron expropiados e indultados.

Otras revueltas, que aunque no tuvieron efecto directo sobre Mérida, fueron las emprendidos por los negros esclavos de la jurisdicción de Coro, la primera iniciada por el zambo Andresote y otra por un negro esclavo llamado J osé Leonardo Chirinos ${ }^{24}$, quienes atacaron a los dueños de haciendas y esclavos de aquella jurisdicción con sangrientas ejecuciones, que dejaron una profunda huella entre los lugareños ${ }^{25}$, que incidieron profundamente en la actuación de los corianos detereminado su falta de adhesión a los movimientos independentistas que se experimentarían en los puertos de aquella zona, los cuales repercutirían en Mérida, especialmente por la actuación del alto clero que regía aquella vicaría.

Después de sofocadas aquellas rebeliones y principios del siglo XIX, fue nombrado como obispo de Mérida, Monseñor Santiago Hernández y Milanés, oriundo de Mier de Salamanca, formado en el colegio mayor de San Bartolomé de aquella localidad, fue electo como obispo de la expresada diócesis el 14 de marzo de 1801 y consagrado por el obispo de Caracas Monseñor Francisco Ibarra en 1802, tomó posesión del obispado en septiembre del mismo año (LABASTIDA, 1983, p. 11-18). La

23 Sobre los comuneros de El Socorro existe una numerosa bibliografía, al respecto revísese a Indalecio (LIÉVANO AGUIRRE, 1980, 1981).

24 Sobre la visión historiográfica de la rebelión de José Leonardo Chirinos véase a: Ramón AIZPURUA (1988, p. 705-723).

25 [...] la rebelión fue dirigida por J osé Leonardo Chirinos y J osé Caridad González, negros libres influidos por las ideas de la revolución francesa y por la guerra de las razas de Santo Domingo. Incitaron a los esclavos y trabajadores de color, trescientos de los cuales se alzaron en rebelión en mayo de 1795, proclamando la "ley de los franceses, la republica, la libertad de los esclavos y la supresión de los impuestos de alcabala y otros que se cobraban a la sazón”. (LYNCH, 1976, p. 217). 
actuación del primado estuvo dirigida por su estricta formación, cuyos ideales estaban regidos por su fidelidad al rey y la monarquía. En su actuación al frente de la diócesis emeritense, emprendió la organización del seminario conciliar, al igual que el cabildo catedral integrado por relevantes personajes como lo eran los doctores Mariano de Talavera y Garcés, Francisco Antonio Uzcátegui, Ramón Ignacio Méndez de la Barta, Mateo J osé Mass y Rubí y el deán Francisco J avier de Irastorza.

El obispo Milanés inició su visita pastoral a su diócesis, y en 1806, se hallaba realizándola en el pueblo de Cumarebo en la jurisdicción de Coro, y coincidió con la llegada de Francisco de Miranda al puerto de la Vela, al mando de dos goletas, intentando iniciar un movimiento independentista ${ }^{26}$. Entonces, los lugareños recordaron los sangrientos eventos ocurridos durante las sublevaciones acaudilladas por Andresote y J osé Leonardo Chirinos, y se opusieron al intento de Miranda, temiendo la reedición de aquellos violentos sucesos. En aquella contingencia, el obispo Milanés salió inmediatamente de la vicaría de Coro y se trasladó a Trujillo27, donde emitió una carta pastoral censurando duramente a Miranda, calificándolo con duros epítetos, al mismo tiempo que conminaba a los feligreses a rechazar por la fuerza a los enemigos de la Corona española ${ }^{28}$.

Fracasado el intento de Miranda, la rebelión de los blancos criollos de Caracas en 1808, no tuvo repercusiones en Mérida, pero dos años después el 19 de abril de 1810, el capitán general de Venezuela don Vicente Emparan fue depuesto en aquella ciudad y luego se procedió delegar el poder político en una Junta Defensora de los Derechos de Fernando VII. Esta fue la primera vez, que las doctrinas populistas hicieron su aparición efectiva en lo que sería la actual Republica de Venezuela. La discusión sobre la fuente de la soberanía en sus vertientes divina y popular se hizo

26 [...] En el día/ tres del presente mes en el que desembarcó Miranda en el / puerto de la Vela de Coro nos hallávamos en Cumarebo, siete/ leguas del oriente de dicho Puerto prosiguiendo nuestra vicita/ pastoral; en la noche del mismo día resibimos un oficio en el que/ el Ynvasor injusto nos convida a una conferencia [...] AAM. Sección 45B Libros Varios. Libro de órdenes y decretos superiores de los Ilustrísimos Obispos Santiago Hernández Milanés y Rafael Lasso de la Vega. Años 1807-1828. Carta pastoral del obispo Santiago Hernández y Milanés a los fieles. Carache, 18 de agosto de 1806. f. 11v-14v.

27 [...] Finalmente havemos caminado/ ciento treinta leguas sin dar lugar al descanso, ya acompañado/ solamente de nuestro confesor, havemos logrado estar con vo/ sotros hoy que os saludamos desde Carache, primera feligrecía/ del Obispado por la parte de Truxillo [...]. (AAM. Sección 45B).

${ }^{28}$ El obispo Hernández y Milanes se expresaba en estos términos: ....Despreciad las ofertas lisongeras de ese engañador,/ volved buestros ojos a los acontesimientos recientes de la/ Francia, animaros, pues que el Señor está con vosotros, y / no consintáis en que uno tan solo de vosotros siga las vande/ras enemigas, y con eso sólo havéis vencido. Si llega á/ vosotros cualquiera papel seductor, en el instante nos/ lo presentaréis, ó a los jueses públicos, so la pena de esco/munión mayor late Sententiae, so la pena de que no seréis ya miembros de nuestra Yglecia de que, ya no sois nuestros le/ xítimos hijos, sino espurios, y malditos de Satanás [...] (AAM. Sección 45B). 
presente entonces en el seno de los criollos caraqueños, quienes se apresuraron a enviar delegados con comunicaciones a las ciudades de la provincia solicitándoles su adhesión.

En Mérida, aquella petición fue acogida con beneplácito por el cabildo secular de la ciudad y el 16 de septiembre de 1810, se conformó la J unta Defensora de los Derechos de Fernando VII, integrada por don Ignacio Antonio Picón y los canónigos del cabildo catedral don Mariano de Talavera y Garcés y Francisco Antonio Uzcátegui29. Ante la misma el obispo Milanés juró fidelidad al monarca español. Las medidas inmediatas tomadas por los juntistas revelaron las razones que animaban a sus integrantes, la primera declarar a Mérida como capital de provincia independiente de Maracaibo, reclamando la categoría que le había sido arrebatada en el siglo XVII y consecuentemente también elevaron el colegio seminario conciliar a la condición de Real Universidad de los Caballeros de Mérida.

Los sucesos posteriores se escenificaron en Caracas, donde en mayo de 1811, fue convocado el primer Congreso Constituyente de Venezuela, con la asistencia de siete de las provincias: Caracas, Cumaná, Margarita, Barinas, Mérida, Trujillo y Barcelona, cuyos delegados declararon el 5 de julio de aquel año la independencia de la República de Venezuela. Entre tanto, Coro, Maracaibo y Guayana se mantenían adversas a esa tendencia y optaron por el bando monárquico. A partir de aquel evento, se evidenciaron la ruptura de los lazos de proximidad dentro los miembros del ayuntamiento eclesiástico, porque adicionalmente a don Mariano de Talavera y Garcés y don Francisco Antonio Uzcátegui también se pronunciaron a favor de la separación de España los canónigos Buenaventura Arias y Ramón Ignacio Méndez de la Barta. En oposición a los anteriores, se identificaron como monárquicos el obispo Hernández y Milanés, el deán Irastorza y el canónigo Mass y Rubí. La constitución fue jurada por el Arzobispo de Caracas Monseñor Narciso Coll y Prat y con muchas reservas también fue jurada por el obispo de Mérida, después que en el seno cabildo catedral fuera debatido el asunto y la mayoría de sus miembros optaron por su aprobación ${ }^{30}$.

29 Las actas de las J untas Conservadoras de los derechos de Fernando VII, fueron publicadas por: Tulio FEBRES CORDERO, T. L Actas de la independencia de Mérida, Trujillo y Táchira en 1810. Y Archivo de Historia y Variedades.

30 Entre otras consideraciones los consultados expusieron el siguiente criterio: ... Es moralmente imposible que el Señor Don / Fernando 7. (aún suponiéndolo vivo) rompa/ las cadenas del cautiverio con que lo aprisiona Na-/ poleon, atendida la ambición de este tirano, y se resti-/tuya al trono de España con su antigua libertad/ considerada la actual ocupación de casi toda la Pe/ nínsula por los Franceses. ¿De qué utilidad, pues, podrá/ ser á los Pueblos haber jurado un Rey imaginario/ que ni puede gobernarlos, ni defenderlos, ni aún/ comunicar con ellos, y que por llamarlo su Rey quedan/ en la anarquía, sujetos á qualquier injusto inva-/sor se haga su dueño?/ ...AAM. Sección 45B Libros Varios. Libro Lora-Milanés. Oficiales 1777-1812. Contestación de los canónigos del Cabildo Catedral de Mérida, Pbro. Dr. Buenaventura Arias y Pbro. Dr. 
La reacción realista y el avance de las tropas de Maracaibo sobre las provincias republicanas fue inmediata, y a principios de 1812, ocuparon el Tocuyo (O'LEARY, 1952, p. 96-99). Pero, el 25 de marzo de 1812, un terrible sismo estremeció las principales ciudades patriotas, Caracas, Barquisimeto, Trujillo y Mérida quedaron en ruinas. Entonces la prédica de los clérigos realistas quienes sostuvieron que el devastador terremoto era un castigo del cielo por haberse revelado contra la autoridad divina del monarca. En Mérida, la gran intensidad del sacudimiento telúrico arruinó la ciudad y fallecieron numerosas victimas, incluyendo al obispo de la diócesis el doctor Santiago Hernández Milanés. Ese terrible sismo dejó arrasadas y demolidas las principales edificaciones de la urbe y constituyó un trágico preludio que determinó la finalización de aquel periodo que la historiografía tradicional ha denominado la primera república (LABASTIDA, 1983, p. 16).

La ocupación realista sobre las ciudades que habían auspiciado la declaración de la independencia fue sangrienta. Especialmente, la ciudad de las cumbres nevadas fue testigo de la llegada de los realistas, quienes se acogieron a la versión de que el terremoto había sido un castigo del cielo en contra de los que se habían rebelado contra su legítimo monarca31. Esa ocupación estuvo acompañada de persecuciones, privaciones, confiscación de bienes y asesinatos de los patriotas por los realistas. Al mismo tiempo, connotados emeritenses abandonaron sus residencias para escapar de la persecución. Asimismo, los merideños tuvieron que asistir al triste espectáculo de ver a su alto clero, a excepción del deán Francisco Xavier Irastorza y el canónigo Mass y Rubí, reducido a prisión en las bóvedas de los castillos de Puerto Cabello y La Guaira (LABASTIDA, 1983, p. 19). Ello, determinó la desintegración del cabildo catedral, mientras el obispado fue declarado en sede vacante por el fallecimiento del obispo Hernández y Milanés. Como consecuencia de esos eventos, se consolidó en la ciudad un fuerte grupo realista, especialmente apoyado y dirigido por el deán Francisco Xavier Irastorza $^{32}$ y el canónigo prebendado de la catedral de origen marabino, el doctor

Francisco Antonio Uzcátegui, a la consulta del Ilmo. Sr. Santiago Hernández Milanés, Obispo de la Diócesis de Mérida de Maracaibo, sobre la conveniencia de jurar o no la independencia de Venezuela, habida cuenta del juramento de fidelidad al Rey, presentado por el Obispo el 21 de septiembre de 1810, por ante la J unta Superior Gubernativa de la Provincia de Mérida. Mérida, 26 de agosto de 1811. p. 671-679.

31 [...] Castigo del cielo, Castigo del Cielo, mancha vuestra frente el borrón de insólito crimen: os habéis sublevado contra vuestro Rey ¡Dios por esto, os castiga! lo cual equivale a decir: “Dios, que os dio un espíritu inteligente y libre, ha enviado sobre vosotros el ángel de la destrucción: porque no quiere seáis dignos; porque no quiere que seáis libres, porque quiere veros siempre arrastrando la pesada cadena de la esclavitud!, hasta allí se atrevió el fanatismo ignorante, hasta calumniar la religión de Cristo, que es la religión de la libertad, del amor y de la dignidad!... (MONSANT, 1983, p. 14-15).

32 ... había en el Cabildo Eclesiástico un Canónigo que mal de su grado residía en esta ciudad. Muerto el Prelado y quedando el de Presidente del Capítulo, pues no era otro sino el Deán 
Mateo J osé Mass y Rubí. Después del terremoto, esos personajes consideraban que Mérida era muy inestable para sus personas e ideas, por ello expresaron sus intenciones de abandonar y trasladar la sede episcopal a Maracaibo, ciudad que se había mantenido fiel a la causa realista, junto a la catedral, el seminario y el convento de monjas Clarisas. Con esa acción separaban las instituciones eclesiásticas más relevantes de la patriota Mérida para asentarlas en la muy noble leal y realista Maracaibo (LABASTIDA, 1983, p. 19).

Aquellas intenciones del clero realista fueron efectuadas con rapidez debido a los acontecimientos que se suscitaron en el año de 1813. A principios del mismo, el coronel Simón Bolívar, invadió el territorio venezolano, con refuerzos militares que se le habían proporcionado en la Nueva Granada y avanzó sobre La Grita y Mérida, la que ocupó en mayo (O’LEARY, 1952, p. 155-160), donde el cabildo secular le otorgó el título de libertador, le facilitó pertrechos, 500 soldados y le entregó 30.000 pesos en oro (FEBRES CORDERO, 1930, p. 286-288). La campaña militar avanzaría hasta Trujillo, donde emitió su celebre decreto de guerra a muerte y finalmente ocupó Caracas restableciendo la republica. Pero, esas victorias patriotas fueron seguidas por terribles y sangrientas derrotas que ocurrieron el año de 1814, con la sangrienta insurgencia de Boves y nuevamente Mérida fue ocupada por los realistas.

En 1815, fue electo obispo para la diócesis de Mérida, Monseñor Rafael Lasso de la Vega, y consagrado un año después por el Arzobispo de Santa Fe de Bogotá, Juan Bautista Sacristán, oriundo de Santiago de Veraguas, en Panamá y formado en el colegio de Nuestra Señora del Rosario de Santa Fe de Bogotá. El prelado Lasso había jurado fidelidad al rey de España ${ }^{33}$, y mantuvo inconmovible su posición monárquica desde entonces. En 1817, durante su estancia en la ciudad serrana, el prelado pudo constatar la restauración de las edificaciones religiosas que habían sido dañadas por el terremoto, entre ellas, parte el seminario y del convento de Clarisas.

Además, el primado sintió el rechazo de la comunidad emeritense, el cual se asentaba en dos razones: la primera, que era irritante para la población la actitud del prelado en mantener la sede episcopal y el seminario en Maracaibo. Esa actuación del obispo se realizaba desconociendo deliberadamente el pronunciamiento de la corte

Francisco Xavier Irastorza, inició con el pretexto del lamentable estado en que había quedado Mérida, un trabajo constante y tenaz para trasladar a Maracaibo la capital de la Diócesis, La Universidad y Seminario y el Convento de Clarisas [...]. (MONSANT, 1983, p. 15).

33 [...] prestó juramento de fidelidad a las constituciones del Colegio del Rosario, en el cual tenía de ajustarse a la doctrina de Santo Tomás, doctrina que moldeara su perfil intelectual y hacía la cual se inclinará su convicción personal; y el juramento de fidelidad al Rey y a la Corona, al cual estaba obligado por sistema de patronato, en el momento que recibió el beneficio como canónigo doctoral de la Catedral de Bogotá en 1804 y posteriormente la dignidad de Chantre de la Catedral de Panamá en 1814 [...] (PEÑA ROJ AS, 2000, p. 67). 
española al respecto, ratificando que... la silla episcopal residiera en Mérida [...] (LABASTIDA, 1983, p. 22) y que aquella autoridad civil, había decretado perpetuo silencio a Maracaibo sobre el derecho de preferencia, circunstancia que fue avalada al mantener su residencia en aquella ciudad lacustre.

La otra razón que separaba al pastor de su grey, radicaba en la tenacidad con que condenaba la proclamación de la Independencia. El obispo consideraba que esa acción sería objeto de sanción divina, idea que expresaba en el púlpito de las Clarisas, el cual había sido habilitado para la misa dominical del prelado. El predicador se expresaba al respecto en las siguientes palabras [:..], merideños, tened entendido que la insurrección a nuestro legítimo monarca es pecado mortal... (LABASTIDA, 1983, p. 22). Esas exhortaciones fueron respondidas con desprecio por los emeritenses, quienes consideraron que el obispo ... bien pudiera irse con su rey al c....

A partir de 1819, y como consecuencia del avance de los patriotas, quienes tomaron Guayana, allí se convocó el Congreso Constituyente de Angostura, en 1819, a partir del cual se creo la Gran Colombia (LYNCH, 1976, p. 240-243). Las sucesivas victorias de los republicanos, motivaron la convocatoria del Congreso Constituyente de Cúcuta en 1821, adonde debió concurrir el obispo Lasso de la Vega, quien fue nombrado diputado por Maracaibo (LABASTIDA, 1983, p. 23-24). En el seno de aquel cuerpo deliberante se le exigió que jurara obediencia a la constitución, lo cual colocaba al primado en conflicto de las fidelidades, porque en 1804, había jurado la fidelidad al rey de España. La negativa del purpurado, motivo encendidas diatribas en su contra e inclusive se pidió su destierro y declarar la sede vacante.

En la resolución de ese conflicto, intervinieron varios factores, el primero una entrevista sostenida entre Monseñor Lasso con el Libertador, en la cual aparentemente se le garantizó su seguridad y le disiparon las dudas acerca del ministerio sacerdotal. Otro factor, que influyó sobre el primado fueron las modificaciones políticas que se habían experimentado en la península con el juramento de la constitución de 1812 por Fernando VII las medidas secularizantes emitidas por las cortes de Cádiz (PEÑA ROJAS, 2000; PERNALETE, 2006). Indudablemente, lo determinante fue la irreversible pérdida del absolutismo y la imposición de las ideas republicanas para que el obispo Lasso jurara la constitución en 1821 (PEÑA ROJAS, 2000, p. 84 ). Finalmente, se le consultó, sobre la definitiva sede de la catedral, el colegio seminario y el convento de monjas, y el prelado se pronunció a favor de Maracaibo, pero los diputados decidieron que la sede episcopal retornaría a Mérida, con el seminario y la universidad. 


\section{El Conflicto por la Independencia en la Clausura}

En la primera década del siglo XIX, el monasterio de San J uan Bautista de la Orden de Santa Clara contaba más de un siglo y medio de haberse establecido en Mérida, el claustro se había establecido aceptando la regla de Santa Clara, basada sobre la tríada básica de las comunidades monásticas, los votos de pobreza, castidad y obediencia. En el caso específico de las Clarisas de Mérida, sus fundadores lo sometieron a la obediencia del obispo diocesano, a cuya autoridad acataban las monjas en todos los órdenes de su vida conventual (RAMÍREZ MÉNDEZ, 1994).

En lo interno, la autoridad era ejercida por la abadesa y la vicaria, quienes regían una convivencia armónica de una comunidad que llegó a sumar la cantidad de ochenta mujeres, entre monjas profesas de velo negro y blanco, donadas, sirvientas y esclavas, las que habitaban el edificio más grande construido en la ciudad de la sierras nevadas durante la época colonial. Las instrucciones precisas de convivencia en la colectividad de las Clarisas les preceptuaban un tratamiento respetuoso y comedido entre sus miembros, no obstante que en ocasiones se presentaran fricciones entre las madres y sus sirvientas o entre las mismas monjas profesas, ello no representaba la ruptura de los lazos de proximidad que animaban la institución creada para convivir y elevar eternamente las oraciones por aquellos que no lo hacían (RAMÍREZ MÉNDEZ, 1994).

En 1810, el convento de Clarisas de Mérida, como participes de una sociedad polarizada, en base a los anteriormente expresados acontecimientos que definieron el proceso independentista, como miembros de esa elite, no estuvieron ajenas a tal enfrentamiento y asumieron posiciones que las condujeron a la ruptura de la proximidad y la fractura de su institución por más de diez años. A pesar de tales diferencias, el comportamiento de las monjas fue firme para enfrentar circunstancias de extrema dificultad, especialmente con el objetivo de salvaguardar la integridad de la comunidad y los principios sociales y religiosos bajo los cuales se instituyó el monasterio.

La situación política que experimentó el convento, al igual que Mérida a partir de 1810, estuvo caracterizada por su extrema inseguridad, originada por las actuaciones políticas y militares de los bandos contendientes. Después del terremoto de 1812, se inició la discusión acerca de la traslación de las monjas, a pesar de que el edificio del monasterio no había experimentado severos daños, el deán Irastorza ${ }^{34}$ ordenó la

34 ... había en el Cabildo Eclesiástico un Canónigo que mal de su grado residía en esta ciudad. Muerto el Prelado y quedando el de Presidente del Capítulo, pues no era otro sino el Deán Francisco Xavier Irastorza, inició con el pretexto del lamentable estado en que había quedado 
mudanza de la catedral, el seminario y en particular el convento de monjas a San J uan de Lagunillas ${ }^{35}$, el cual fue trasladado a un edificio techado de paja, en la espera de que finalizarán los sucesivos movimientos telúricos y se repararan los daños al claustro de Mérida.

Durante ese período, la idea de la traslación del monasterio fue conocida y debatida por las religiosas, generando la existencia de dos bandos, uno, el de las que propugnaban la salida hacia Maracaibo, dirigidas por la priora María Sebastiana del Santísimo Sacramento junto a las monjas maracaiberas y otras oriundas de distintas ciudades del obispado. Mientras las nativas de Mérida se negaron a abandonar la ciudad, en medio de las... más extrañas y lamentables confusiones... ${ }^{36}$.

Con la intención de cumplir su cometido, el prebendado Irastorza, ordenó realizar una consulta a las monjas para conocer su opinión acerca de la traslación. La respuesta de las religiosas que deseaban permanecer en Mérida fue respaldada en las consideraciones que se hallaban sin fuerzas para acometer tan difícil periplo y consideraban innecesario realizar tal modificación, la cual contradecía las motivaciones fundamentales que habían sido autorizadas por las dos autoridades que autorizaron la fundación del monasterio: la pontificia y la real. Además, las Clarisas razonaban que el convento había sido dotado por los habitantes de Mérida para beneficiar a las emeritenses y que a consecuencia de su traslación se favorecerían a extraños que no habían sido sus promotores. Por último, se significó que sin los auxilios espirituales de las monjas y cuidado permanente de sus capitales, éstos se aniquilarían destruyendo totalmente las rentas del convento.

De la misma forma, las Clarisas con el objetivo de evitar la traslación, se dirigieron al Tribunal Eclesiástico del Obispado, apoyadas por el clero patriota, cuyos sacerdotes actuaron inmediatamente para impedir que tal providencia se hiciera efectiva. A pesar de la ausencia de las dignidades episcopales, los clérigos J osé Luis Ovalle de El Morro, Salvador León de El Llano, Antonio Escalante de La Punta, J osé Manuel Lobo de Acequias y Juan de la Parra de J ají, en nombre de todos los presbíteros del Obispado, exceptuando a los de Coro y Maracaibo, apoderaron a don Francisco Picón, para que asumiera la defensa de las monjas ante el Cabildo Eclesiástico de Mérida, oponiéndose al traslado de la catedral, seminario y convento de religiosas a la

Mérida, un trabajo constante y tenaz para trasladar a Maracaibo la capital de la Diócesis, La Universidad y Seminario y el Convento de Clarisas [...]. (MONSANT, 1983, p. 15).

35 AAM. Sección 54. Religiosas. Caja 12. Doc. 54-0269. Expediente para justificar las causas necesarias o evidentemente útil para el traslado perpetuo del Convento de Santa Clara de Mérida a Maracaibo. Mérida, 21 de agosto de 1816. f. 56.

36 AAM. Sección 54. Religiosas. Caja 12. Doc. 54-0269. Expediente para justificar las causas necesarias o evidentemente útil para el traslado perpetuo del Convento de Santa Clara de Mérida a Maracaibo. Mérida, 21 de agosto de 1816. f. 56. 
ciudad de Maracaibo (AAM. Sección 54). Cuando el conflicto fue planteado en el tribunal eclesiástico, donde las Clarisas hicieron presentes sus legítimas alegaciones, obtuvieron por respuesta que fueran sometidas a perpetuo silencio, con excesivas penas y censuras, si no desistían de su pretensión. En aquella instancia, se les amenazó con relevarlas de los cargos, negándoles licencia para celebrar capítulo de elecciones de abadesas y los demás oficios de comunidad.

Al mismo tiempo que las religiosas intentaban impedir su traslado, los realistas se dirigieron al gobernador Cajigal, con el fin de obtener la autorización, explicándole la delicada e insegura situación política de Mérida, argumentado la pérdida de vidas y edificios ocasionada por el terremoto, lo cual justificaba la realización del traslado. Asimismo, impidieron con siniestras maquinaciones la reconstrucción de la urbey sus templos ${ }^{37}$.

Esa solicitud fue respondida mediante una Real Orden del Consejo de Regencia fechada en Cádiz a 3 de julio de 1813, en la cual se ordenaba la inmediata traslación de la catedral, colegio seminario y convento de monjas desde Mérida a Maracaibo, disposición que fue acatada por el gobernador de Maracaibo, don Fernando Miyares, quien ordenó al capitán don Sebastián de la Calzada que procediera al traslado inmediato de las monjas, sus alhajas, rentas y vasos sagrados; recurriendo para ello a todos los auxilios y emitiendo las censuras necesarias contra aquellos que se opusieran a esa medida, pero se otorgaba la facultad de que aquellas monjas, ancianas y enfermas que deseasen permanecer en Mérida o bien trasladarse a otros conventos, lo hicieran ${ }^{38}$.

Otras actuaciones fueron elevadas por los patriotas ante la Real Audiencia de Caracas, que temporalmente despachaba en Valencia. El retardo procesal causado por la conmoción política, impidió que el tribunal decidiera prontamente sobre el asunto. Esa dilación, fue aprovechada por las autoridades eclesiásticas monárquicas, quienes apresuraron el viaje de las conventuales, dispusieron las cabalgaduras, recogieron los enseres e hicieron las valijas. Cuando todo estaba listo y preparado para el traslado de las religiosas, un día antes de la fecha fijada para la partida, llegó un correo portado por un chasqui, procedente de Valencia, quien entregó dos Reales Provisiones ordenando la permanencia en Mérida de la catedral, el seminario y el convento de monjas, hasta

37 [...] El Gobernador de Maracaibo y el Cabildo Eclesiástico impedían de todos modos la reconstrucción de Mérida! El primero dice el Fiscal Costa, prohibiendo que se edificaran casas u otra cualquiera obra hasta que se evacuasen los informes que se pedían sobre la reedificación de la ciudad y el segundo impidiendo con medios dilatorios la reedificación de templos [...]. (MONSANT, 1983, p. 16-17).

38 AAM. Sección 54. Religiosas. Caja 11. Doc. 54-0257. Expediente de traslación de las monjas de Santa Clara de Mérida a Maracaibo. Mérida, 1815-1818. f. 36. 
tanto no lo determinase el supremo gobierno de la nación ${ }^{39}$, lo que temporalmente paralizó la medida.

En 1813 se estableció segunda república, la cual se inició con la invasión de Bolívar desde la Nueva Granada, provocando la huida del alto clero realista a Maracaibo. Entonces, el señor doctor don Buenaventura Arias, único canónigo de la catedral que permanecía en Mérida, fue comisionado para estudiar la situación del monasterio. En consecuencia, pudo apreciar que la priora tenía su plazo vencido y autorizó la elección de una nueva abadesa, cuyos sufragios presidió y al mismo tiempo ordenó el retorno de las religiosas desde el pueblo de San J uan a Mérida el 1 de junio de ese año, lo cual indica que lo narrado por don Tulio Febres Cordero acerca de Anastasia la criada del monasterio de Clarisas y la llegada de Bolívar a Mérida es incierto porque las monjas se hallaban en aquel poblado en mayo del año 1813 (FEBRES CORDERO, 1983, p. 72-75). A partir de la anterior fecha se mantuvieron pacíficamente en el monasterio de Mérida por dos años hasta la restauración de los realistas en la ciudad, al mando del capitán Sebastián de la Calzada.

\section{La Consumación del Cisma}

Dos años después, en 1815 regresó a Mérida el prebendado Mateo Mass y Rubí con una orden del provisor y dos provisiones del Consejo de Regencia ${ }^{40}$, mediante las cuales se ordenaba el inmediato traslado de las monjas de Mérida a Maracaibo. El mismo canónigo fue encargado para efectuar la traslación, y notificó a las religiosas de su inminente abandono de Mérida. Asimismo, el deán expresó que disponía de una casa segura y capaz en Maracaibo para que éstas realizaran su vida conventual, y se le concedió licencia para elevar un altar portátil destinado a celebrar el santo sacrificio de la misa y las confesiones de las religiosas ${ }^{41}$.

$\mathrm{Al}$ conocer esa intimación, las madres nuevamente le ratificaron su posición y expresaron que había muchas profesas enfermas, ancianas y achacosas que no podrían viajar a Maracaibo. Por esas razones se excusaron para salir de Mérida. Esas justificaciones ocultaban el verdadero motivo de la negativa de la comunidad para abandonar Mérida. Así se evidenció, que definitivamente se habían roto los lazos de proximidad de las monjas al fragmentarse en dos bandos: monárquicas y patriotas.

39 AAM. Sección 54. Religiosas. Caja 12. Doc. 54-0269. Expediente para justificar las causas necesarias o evidentemente útil para el traslado perpetuo del Convento de Santa Clara de Mérida a Maracaibo. Mérida, 21 de agosto de 1816. f. 56.

40 AAM. Sección 54. Religiosas. Caja 11. Doc. 54-0257. Expediente de traslación de las monjas de Santa Clara de Mérida a Maracaibo. Mérida, 1815-1818. f. 36r.

41 AAM. Sección 54. Religiosas. Caja 11. Doc. 54-0257. Expediente de traslación de las monjas de Santa Clara de Mérida a Maracaibo. Mérida 1815-1818. f. 36r. 
Mientras las marabinas, Sebastiana del Santísimo Sacramento, J osepha de J esús María Monsón y Mass y Rubí, hermana y sobrina del canónigo de catedral Matheo de Mass y Rubí, J osepha de la Virgen María Carmona y Lugo; las barinesas Trinidad del Carmen y Ana María de San J osé Roca Cuéllar; la trujillana María de J esús de San J osé de la familia Briceño y la merideña Andrea de la Merced Briceño Rincón y otras tres donadas para un total de diez religiosas optaron por el bando realista y en consecuencia trasladarse a Maracaibo en 1815.

El otro grupo formado por dieciséis religiosas patriotas, entre las cuales estaban la madre presidenta Clara de San Ignacio Rivas y Paredes, quien era tía del coronel Rivas Dávila, María Encarnación Briceño, familiar de los patriotas trujillanos Antonio y Nicolás Briceño, Ángela Regina de la Santísima Trinidad, Nicolasa del Cristo y María de las Nieves de San José, familiares de Cristóbal y Juan José Mendoza, Antonia de J esús, hermana del entonces vicario y posterior arzobispo de Venezuela, doctor Ignacio Fernández Peña y María J oaquina de la Concepción Méndez de la Barta, hermana del canónigo y también posterior arzobispo Méndez Barta, se negaron a abandonar Mérida y mantuvieron el monasterio en la ciudad. Esas facciones de las Clarisas fueron conocidas por el pueblo y motivaron un estribillo, en el cual se atestiguaba que las oraciones de las Clarisas se dirigían al Señor, unas por el Rey de España, don Fernando VII y otras por el Libertador Simón Bolívar².

A pesar del dolor que se causaba con la separación de la venerable comunidad, la autoridad del deán se impuso y a partir del 19 de abril de 1815, se iniciaron los preparativos para el viaje de las Clarisas. Con tal finalidad, se dispusieron las cabalgaduras, se tomaron los vasos sagrados, entre los que se contaban un pissis, un cáliz, un ornamento de cada color y se sustrajeron 11.350 pesos, fincados en la ciudad de Maracaibo y 2.000 pesos que reconocía don Martín Briceño, vecino de la ciudad de Mendoza para el sustento de las monjas próximas a emigrar ${ }^{43}$.

El 2 de mayo se consumó el cisma, en medio de la más triste amargura y dolor, las que se marcharon tuvieron que atravesar los profundos y crecidos ríos de la cordillera amenazadas militarmente. Entre tanto, las ancianas y enfermas fueron apoyadas por las más jóvenes. En general, durante aquel incierto viaje, toda la comitiva se mantuvo en zozobra y al llegar a Timotes debieron detenerse porque la madre J osefa de J esús María, quien ya iba enferma se agravó y falleció, siendo enterrada en la iglesia parroquial de ese pueblo. Después de todas esas vicisitudes, la comunidad llegó a

42 El estribillo decía así: Las Clarisas están rezando; en abierta oposición; unas piden por Fernando; otras rezan por Simón.

43 AAM. Sección 54. Religiosas. Caja 11. Doc. 54-0257. Expediente de traslación de las monjas de Santa Clara de Mérida a Maracaibo. Mérida 1815-1818. f. 36r. 
Maracaibo el 21 de mayo. Después de desembarcar en el puerto de la ciudad lacustre, fueron recibidas por una nutrido grupo en el que se juntaron pueblo y la nobleza de la ciudad encabezado por el gobernador y el provisor del obispado, quienes al ver a las madres las aplaudieron, luego se les condujo con todo el respeto al monasterio que había sido construido para ellas. Al mismo tiempo, se mantuvo en cargo de abadesa a María Sebastiana del Santísimo Sacramento, la hermana del canónigo Mass y Rubí (AAM. Sección 54).

Posteriormente, el 28 de mayo de 1815, se emitió un decreto firmado por el Déan Irastorza, provisor del Obispado, prohibiendo a la religiosas que quedaron en Mérida, la celebración de capítulo para la elección de abadesa, asimismo, autorizaba realizar tales actos en Maracaibo, también dispuso una nueva redistribución de los vasos sagrados y los capitales y rentas del monasterio. Esa medida se consolidó el 13 de noviembre de 1815, cuando se efectuó el capítulo de elección de abadesa en la ciudad lacustre, en el cual se ratificó por priora a María Sebastiana Mass y Rubí y posteriormente el 27 del mismo mes recibieron la visita del nuevo obispo electo monseñor Rafael Lasso de la Vega.

Inmediatamente después de esta visita, el obispo tomó una determinación que afectaba notablemente al monasterio de Mérida, a pesar de que el número de sus religiosas era mayor, así como sus capitales y rentas, el 9 de diciembre de 1815, el prelado decidió que la comunidad emeritense se degradaba a la condición de hospicio, impidiendo con ello la elección de abadesa y vicaria. Entretanto, sólo tendrían una presidenta y se asignarían los oficios temporales, además, se vedaban el ingreso de nuevas profesas al monasterio en Mérida (AAM. Sección 54). Esa medida fue refutada por Clara de San Ignacio de Rivas Paredes, presidenta del claustro emeritense, solicitando la derogación de la providencia, ante cuya solicitud el prelado les conminó nuevamente a cumplir su voto de obediencia.

Un año más tarde, el 6 de septiembre de 1816, el obispo Rafael Lasso de la Vega procedió a efectuar la visita al Monasterio de Mérida, y se realizó la elección de la presidenta del convento y se designaron los oficios respectivos. Al igual que fomentó la separación de las Clarisas, divididas en dos comunidades, una, en aquella ciudad del lago, y las que permanecían en Mérida. Con ello, se evidenciaba la manifiesta intención del obispo en trasladar definitivamente y totalmente a todas las monjas Clarisas que aún permanecían en Mérida a Maracaibo, lo cual le llevó a solicitar la opinión de las vicarías de Pamplona, Cúcuta, La Grita, San Cristóbal, Barinas, Trujillo, Casigua, Coro, Mérida y Maracaibo. En respuesta a esa consulta los vicarios de las primeras, resaltaron las condiciones favorables para la permanencia del claustro en Mérida por su agradable 
clima, la abundancia de alimentos y agua, a diferencia de lo que se experimentaba en Maracaibo. Adicionalmente, se esgrimía la larga permanencia por más de 150 años del claustro en la ciudad, y que este había sido un esfuerzo de los emeritenses, quienes lo habían dotado y mantenido a lo largo de ese período ${ }^{44}$. Adicionalmente, es preciso hacer especial énfasis en las aseveraciones del Cabildo emeritense, que aparte de las anteriores consideraciones argumentaron que ello constituía una tropelía del señor vicario capitular, en sede vacante, en contra de los justos derechos que tenían los emeritenses, quienes habían dispuesto de sus peculios para contar con ese claustro de religiosas. Además, argumentaban que la traslación temporal no se había completado porque la mayoría de la comunidad había permanecido en Mérida, y que parte de las que habían partido habían sido obligadas a marcharse contra su voluntad. Lo cual se evidenciaba en que una religiosa, a pesar de estar enferma había sido forzada a seguir a Maracaibo, cuyo destino había sido la muerte a pocos días de salir de Mérida. Por ello, la pretendida traslación sólo podía considerarse como una desmembración de la comunidad clarisa con el único objetivo de proveer a Maracaibo de los beneficios que les aportaba una institución producto del esfuerzo de los merideños.

De la misma forma, explicaban los ediles emeritenses, que la única justificación para realizar tal tránsito hubiese sido la ocupación de la ciudad por infieles, pero que en Mérida, todos eran católicos, apostólicos y romanos. En cuanto a la revolución y la parte que en ella Mérida había tomado, expresaban al vicario capitular, que las fuerzas revolucionarias en ningún momento habían irrespetado la clausura, ni a las reverendas. En cuanto a los daños que había causado el terremoto en el edificio del monasterio, habían sido pocos y ya se habían reparado. Por último, exhortaban al ayuntamiento marabino a realizar otra fundación monástica en aquella ciudad para satisfacer las necesidades de sus mujeres (AAM. Sección 54).

A diferencia de las restantes vicarías, los marabinos se pronunciaron a favor del traslado definitivo de las Clarisas a su ciudad. En su favor, expresaron que habían recibido con todas las comodidades y aprovisionamiento a las religiosas, quienes habían sido muy bien tratadas por el pueblo, y durante la corta permanencia del monasterio en la ciudad ya habían profesado dos religiosas. Lo cual era indicativo de la necesidad de una casa de oración que satisficiera la necesidades de las jóvenes, pero no hicieron alusión a la dotación que se exigía por las disposiciones regias para fundar un convento, ni que la comunidad estuviera dispuesta a proporcionársela. A pesar de que

44 AAM. Sección 54. Religiosas. Caja 12. Doc. 54-0269. Expediente para justificar las causas necesarias o evidentemente útil para el traslado perpetuo del Convento de Santa Clara de Mérida a Maracaibo. Mérida, 21 de agosto de 1816. f. 56r. 
la mayoría de los informes de las vicarías del obispado fueron adversos a la traslación perpetua de las Clarisas desde Mérida a Maracaibo, en abierta contradicción a los juicios emitidos, la opinión del prelado se pronunció por la radicación de las religiosas en esta última ciudad (AAM. Sección 54).

Pero, contrario a la voluntad episcopal, el interés de las autoridades eclesiásticas por establecer definitivamente el monasterio en Maracaibo fue desvaneciéndose en la medida que la causa independentista se imponía en el territorio venezolano. El deán Irastorza, principal promotor de la traslación falleció en 1817. Entre tanto, el obispo Lasso, también favorable a la idea, después de superar el conflicto de las fidelidades, modificó su tendencia política de realista a patriota en 1821. Mientras, el Congreso de Cúcuta, donde concurrieron connotados patriotas vinculados familiarmente con las religiosas emeritenses dispuso que la sede episcopal y el colegio seminario retornarían definitivamente a Mérida.

A pesar de tales disposiciones, la comunidad que había emigrado a Maracaibo no fue reintegrada a Mérida en aquel año. En los años sucesivos a 1821, la comunidad de Clarisas residente en la ciudad del lago experimentó serias dificultades: padecían hambre, problemas de abastecimiento e, inclusive, inseguridad. En vista del abandono y las penurias que padecían, los numerosos problemas que incluían hasta la inseguridad porque las reverendas habían observado que sobre los muros se trepaban personas indecentes que deseaban observar a las madres en sus quehaceres domésticos, al igual que extrañaban el clima y las comodidades que disfrutaban en Mérida. Esas angustias motivaron la decisión de Encarnación de Santa Rita, en dirigir una comunicación a su hermano el doctor Antonio María Briceño, a los efectos que interpusiera su influencia ante el obispo de la diócesis para que se le permitiera su retorno a Mérida.

La solicitud del Dr. Briceño ante el primado a favor de su hermana, ocasionó que el obispo Lasso de la Vega, requiriera información acerca de la situación que experimentaban las monjas residentes en Maracaibo. En respuesta a esa indagación, la abadesa María Sebastiana del Santísimo Sacramento, emitió una comunicación, donde expresaba que no había religiosas para cumplir con los oficios, ni siquiera el de prelada. Asimismo, enunció dolidamente que la mayoría de las madres se hallaban enfermas, y no se realizaban los ejercicios de oración mental. Además, las rentas les eran insuficientes para sostener los gastos del monasterio marabino. En vista de tales penurias, el primado emeritense ordenó la inmediata la restitución de las reverendas residentes en aquella ciudad lacustre en la comunidad de Mérida. 
A tal efecto, se hicieron los preparativos del viaje, a cuyo fin se necesitaron catorce bestias de sillón y veinte de carga y dos sillas de mano porque dos de las monjas estaban obesas. En los primeros días de mayo de 1827, salieron de Maracaibo rumbo al puerto de la Ceiba las reverendas y al llegar allí, la madre Seguí se agravó al sufrir el mal de páramo, al extremo que hubo que administrarle los santos óleos. Después de haber sido asistida, su salud mejoró, pero se determinó que no podía continuar su viaje hasta la ciudad de los cinco picos nevados, por cuya razón fue temporalmente alojada en el monasterio de Regina Angelorum de Trujillo, las restantes madres continuaron su viaje a Mérida, adonde arribaron el 22 del mismo mes, concluyendo de esta forma el cisma que las había separado por más de 11 años (AAM. Sección 54).

\section{Conclusión}

La polarización que originó la guerra de independencia en Latinoamérica, no solamente se dio en el campo político, sino institucional y afectó a los lazos de proximidad que cotidianamente se desplegaban en los diferentes ámbitos, específicamente en el Convento de Santa Clara de Mérida, las monjas se dividieron en monárquicas y republicanas. Esa situación, determinó el cisma de las madres que motivó el traslado de las realistas a un accidental monasterio edificado en Maracaibo, en cuyo recito se asilaron por más de diez años las que decidieron emigrar. Entre tanto, en Mérida se mantuvo la mayor parte de las religiosas y capitales que sostenían el cenobio, a pesar de su importancia y trascendencia histórica en la sede de la ciudad episcopal fue rebajada a la condición de hospicio, vedándole la posibilidad de ingreso de nuevas profesas y la elección de abadesas, prácticas que les eran propias desde su fundación en 1651. A pesar de las reiteradas protestas de las religiosas patriotas ante las prevalecientes autoridades religiosas monárquicas fueron conminadas a guardar silencio al respecto recurriendo a su voto de obediencia.

Ese contexto motivó la ruptura en los lazos de proximidad entre las mujeres que integraban aquella venerable comunidad, indudablemente las madres fueron afectadas no sólo en sus cotidianas relaciones internas sino en su inmenso prestigio social y en la pérdida de sus cuantiosos capitales acumulados a lo largo de mas de un siglo y medio, producto de las dotes de las religiosas que habían ingresado al cenobio. La persistencia de aquella secesión trascendió más allá del periodo conflictivo y se extendió por más de seis años después de finalizado el conflicto, en cuya resolución intervino el congreso de Cúcuta, celebrado en 1821, aunado a la insuficiencia de recursos que enfrentaron las monjas asiladas en Maracaibo, quienes después de la consolidación de la república solicitaron su retorno al convento emeritense , lo que se 
tradujo en la decisión de las autoridades eclesiásticas en reunir a la comunidad en su sede original de Mérida, en 1827.

\section{SIGLAS}

AAM. Archivo Arquidiocesano de Mérida. (Mérida-Venezuela)

AGEM. Archivo General del Estado Mérida. (Mérida-Venezuela)

AGNB. Archivo General de la Nación (Santa Fe de Bogotá- Colombia)

AGI: Archivo General de Indias. (Sevilla - España)

\section{Referencias}

ACADEMIA NACIONAL DE LA HISTORIA. Los Comuneros de Mérida. (Estudios) Edición conmemorativa del bicentenario del movimiento comunero. Caracas, 1981. t. 1. (Fuentes para la historia colonial de Venezuela, 152).

ACOSTA MOHALEM, J osé de J esús. Historia de la Iglesia en Pamplona Siglos XVI, XVII y XVIII. Pamplona: Editorial Ideas Litográficas. Universidad de Pamplona Norte de Santander, 1999.

AGUADO, Pedro de. Recopilación historial de Venezuela. Caracas: Academia Nacional de la Historia. 1963. t. 2. (Colección Fuentes para el estudio de historia colonial 63)

AGUIRRE ELORRIAGA, Manuel. La Compañía deJ esús en Venezuela. Caracas: Editorial Cóndor, 1941.

AIZPÚRUA A., Ramón. La insurrección de los negros de la serranía de Coro. Boletín de la Academia Nacional de la Historia. Caracas, t. 71, n. 283, jul./ sep. 1988.

ARMAS CHITY, J . A. De. Documentos para la historia colonial de los andes venezolanos (siglos XVI-XVIII). Caracas: Instituto de Filosofía. Facultad de Humanidades y Educación Universidad Central de Venezuela, 1957.

ARONSON, Perla. La visión weberiana del conflicto social. Revista Conflicto Social. año1, n. 0, nov. 2008.

ARROM, Silvia Mariana. Las mujeres de la ciudad de México, 1790-1857. México: Editorial Siglo XXI, 1988.

BALDOS CIRIA, Concepción. El imaginario femenino en las independencias americanas. Revista Ómnibus, Año 5, n. 26, mayo, 2009.

BALLESTEROS Y BARRETA, A. Historia de España y su influencia en la historia universal. Barcelona, 1932. t. 9.

BREWSTER, Claire. Género en la Independencia de Latinoamérica II.¿Amazonas o inocentes?. In: DAVIES, Catherine; BREWSTER, Claire; OWEN, Hilary. South American Independence: Gender, Politics, Text. Liverpool: Liverpool University Press, 2006.

BRICEÑO GUERRERO, J osé Manuel. Discurso salvaje. Caracas: Fundarte, 1980. 
CAMPO DEL POZO, Fernando. Historia documentada de los agustinos en Venezuela durante la época colonial. Caracas: Academia Nacional de la Historia, 1968. (Fuentes para la Historia Colonial de Venezuela 91).

CARRERA DAMAS, Germán. La crisis de la sociedad colonial venezolana. Caracas: Monte Ávila Editores, 1983.

CHACÓN, J uan Bosco. F.S.C. La expulsión de los jesuitas y la administración de temporalidades en Mérida 1767-1805. Mérida: Universidad de Los Andes (tesis), 1980.

CHERPAK, Evelyn. La participación de las mujeres en el movimiento de independencia de la Gran Colombia, 1780-1830. In: LAVRIN, Asunción (Ed.). Mujeres

latinoamericanas. Perspectivas históricas. Westport: Greenwood Press, 1978. p. 253270.

COLMENARES, Germán. Historia económica y social de Colombia 1537-1719. Bogotá: Ediciones La Carreta, 1978.

DAVIES, Catherine; BREWSTER, Claire; OWEN, Hilary. South American Independence: Gender, Politics, Text. Liverpool: Liverpool University Press, 2006.

DEL REY FAJARDO, J osé; SAMUDIO, Edda O.; BRICEÑOJ ÁUREGUI, Manuel. Virtud, letras y política en Mérida colonial. Mérida: Universidad Católica del Táchira, 1996. 3v.

DELGADO MARTÍN, J aime. La independencia de América en la prensa española. Madrid: Seminario de Problemas Hispanoamericanos, 1949.

ENCISO RECIO, Luis Miguel. La opinión pública española y la Independencia Hispanoamericana (1819-1820). Valladolid, 1967.

EYZAGUIRRE, J aime. El alcance político del decreto de libertad de comercio de 1811. Boletín de la Academia chilena dela historia, n. 74, primer semestre, 1966. $\overline{1} \overline{9} \overline{7}$. . Ideario y ruta de la emancipación Chilena. Santiago: Editorial Universitaria,

FEBRES CORDERO, Tulio. Las Actas de la independencia de Mérida, Trujillo y Táchira en 1810. In: FEBRES CORDERO, Tulio. Archivo de Historia y Variedades. Caracas: Parra León Hnos, 1930. t. 1, p. 226-253.

FEBRES CORDERO, Tulio. Los tubos del órgano. In: Mérida: Talleres Gráficos Universitarios, 1983. p. 86-90.

FEBRES CORDERO, Tulio. LX Bolívar en Mérida. In: variedades. Caracas: Parra León Hnos. Editores, 1930. t. 1, p. 286-288. . Mitos y tradiciones.

FEBRES CORDERO, Tulio. Un trabucazo a tiempo. In: Mérida: Talleres Gráficos Universitarios, 1983. p. 72-75. . Mitos y tradiciones.

FERNÁNDEZ ALMAGRO, Melchor. La emancipación de América y su reflejo en la conciencia española. Madrid: Hispánica, 1944. 
FERNÁNDEZ LIZARDI, J osé J oaquín: Noticias de las insurgentes mexicanas. In: GARCÍA, Genaro. Documentos históricos mexicanos. México: Instituto Nacional de Estudios Históricos de la Revolución Mexicana, 1985. t. 5, p. 474-478.

FIGUERA, Guillermo. La Iglesia y su doctrina en la independencia de América. Caracas: Academia Nacional de la Historia, 1960. (Biblioteca de la Academia Nacional de la Historia, 33).

FISHER, J . R.; KUETHE, A. J .; McFARLANE, A. (Ed.). Reform and Insurrection in Bourbon New Granada and Peru. Baton Rouge, 1990.

GARCÍA, H. Biografías de los obispos de Mérida. Boletín de la Academia Nacional de la Historia, T. 41, n. 163, mayo, 1958.

GARRIDO ASPERÓ, María J osé. Entre hombres te veas: Las mujeres de Pénjamo y la revolución de Independencia. Disponible en:http:// 132.248.9.9/libroe 2006/ 0988027/ 12_c08.pdf>. Aceso en: 27 dez. 2003.

GINER, J esús. Teorías del conflicto social. Disponible en:<http:/ / es.wikipedia.org/ wiki/Conflicto_social>. Aceso en: 20 nov. 2003.

KENTNER, J anet. The Socio-Political role of women in the Mexican Wars of Independence. Phd. Discuss. Chicago: University de Loyola, 1975.

LABASTIDA, Ricardo. Biografías de los obispos de Mérida. Mérida: Concejo Municipal de Libertador. Edición Conmemorativa de los 425 años de la Fundación de la Ciudad de Mérida, La Imprenta, 1983. (Fuentes para la Historia de Mérida 5).

LAVRIN, Asunción. The Execuxion of the Law of Consolidacion in New Spain Economic Aims and Results. Hispanic American Historical Review, v. 53, n. 1, 1993.

LEAL, Ildefonso. Los jesuitas en Mérida. Revista Historia, Caracas, n. 23, 1965.

LEAL, María Luisa. Mujeres insurgentes. Boletín del Archivo General de la Nación. México, v. 20, n.4, p. 543-604, 1949.

LÉON, J .; BARRIGA, S. et al. Psicología social. Madrid: McGraw Hill, 1998.

LIÉVANO AGUIRRE, Indalecio: Los grandes conflictos sociales y económicos de nuestra historia. Bogotá: Ediciones Tercer Mundo, 1980. t. 1.

LYNCH, J ohn. Las revoluciones hispanoamericanas. 1808-1826. Barcelona: Editorial Ariel, 1976.

MARTÍNEZ REYES, Gabriel. Finanzas de las 44 diócesis de Indias. 1515-1816. Bogotá: Ediciones Tercer Mundo, 1980.

MONSANT, J uan N. P. Resumen histórico de la Universidad de Los Andes. Mérida. Concejo Municipal de Libertador. Edición Conmemorativa de los 425 años de la Fundación de la Ciudad de Mérida, La Imprenta. 1983. (Fuentes para la Historia de Mérida 6). 
MORENO MÁRQUEZ, César. Proximidad, trascendencia y subjetividad en la metafenomelogía de E. Levinas. Disponible en: <http:// revistas.ucm.es/ fsl/ 02112337/ articulos/ ASHF8689120037A.PDF>. Aceso en: 27 dez. 2003.

MORÓN, Guillermo. El proceso integrador de Venezuela. Caracas: Academia Nacional de la Historia, 1977. (El libro menor 3).

MURILLO, Susana. El conflicto social en Michel Foucault. Revista Conflicto Social. año1, n. 0, nov. 2008.

NÚÑEZ, J orge. La revolución francesa y la independencia americana. Nueva Sociedad, n. 103, oct., 1989.

O’LEARY, Daniel Florencio. Memorias. Narración. Caracas: Imprenta Nacional, 1952. t. 1.

PAVÓN VILLAMIZAR, Silvano. Historia del poblamiento y construcción del espacio hispánico en Pamplona. Pamplona: Publicación de la Cámara de Comercio de Cúcuta, 1999.

PEÑA ROJ AS, J uan de Dios. Superación del conflicto de fidelidades en el obispo Lasso dela Vega. Roma: Pontificia Universidad Gregoriana. Facultad de Historia Eclesiástica, (tesis) 2000.

PERNALETE, Carlos. Las Cortes de Cádiz y su ausencia en la historiografía americana. Reflexiones y nuevas lecturas. Boletín de la Academia Nacional de la Historia, t. 89, n. 353, Ene./ mar., 2006.

PICÓN PARRA, Roberto: Fundadores, primeros moradores y familias coloniales de Mérida. Prolegómenos. Los fundadores J uan Rodríguez Suárez y sus compañeros (1558). Caracas: Academia Nacional dela Historia, 1988. t. 1. (Colección Fuentes para la Historia Colonial de Venezuela 197).

QUINTERO, Inés. ¿Fue la independencia una revolución social? 2011. Disponible en: $<$ http:// www.analitica.com/ bitblioteca/iquintero/independencia.asp>. Aceso en: 27 mar. 2011.

RAMÍREZ MÉNDEZ, Luis Alberto. De la piedad a la riqueza. Convento de Santa Clara de Mérida, 1651 - 1874. Mérida: Archivo Arquidiocesano de Mérida, 2005. t. 1. (Fuentes para la Historia Eclesiástica de Venezuela. 4). Oct./ $\overline{\text { Dic., }} 1994$.

Historiografía Colonial de Mérida. Tierra Firme. año 12, n. 48, v. 12,

. La Artesanía colonial en Mérida (Siglos XVI-XVII). Caracas: Academia Nacional de la Historia, 2007. (Fuentes para la Historia Colonial de Venezuela 265).

. La tierra prometida del sur del lago de Maracaibo y la villa de San Antonio $\overline{\mathrm{d}} \overline{\mathrm{G}} \overline{\mathrm{Gi}}$ raltar (Siglos XVI-XVII). Caracas: Editorial La oveja y la rana, 2010. t. 1-2.

RIVERA DE VENTOSA, Enrique. La filosofía en Hispanoamérica durante la época de la emancipación. Revista de Derecho de Valdivia, año 1, n. 1, 1990. 
RODRÍGUEZ SUÁREZ, J uan. Probanza. Mérida: Concejo Municipal de Libertador, 1983. (Colección Fuentes para la Historia de Mérida 1).

SAMUDIO A, Edda O. La Fundación del Colegio de la Compañía de J esús en la Provincia de Venezuela. Dotación de un patrimonio. In: FAJ ARDO, J osé del Rey; ALBERTO GUTIÉRREZ, S. J . La pedagogía jesuítica en Venezuela. San Cristóbal: Universidad Católica del Táchira, 1991. t. 2. p. 530-536. dèl Táchira, 1996.

. Virtud, letras y política en la Mérida colonial. Mérida: Universidad Católica

. De la ermita de Nuestra Señora del Pilar de Zaragoza al convento de San Francisco. Caracas: Academia Nacional de la Historia, 2007. (Colección fuentes para la historia colonial de Venezuela 261).

. El Colegio San Francisco J avier en la Mérida colonial. Germen histórico de la Universidad de Los Andes. Mérida: Ediciones del Rectorado de la Universidad de Los Andes, 2003. t. 1.

. La élite capitular de Mérida. In: AMODIO, Emanuele (Comp.). Vida cotidiana en Venezuela durante el siglo XVIII. Maracaibo: Gobernación del Estado Zulia y Universidad del Zulia, 1999. p. 147-170.

. La villa de San Cristóbal en la provincia de Mérida durante el dominio hispánico. San Cristóbal: Universidad Católica del Táchira. Centro de desarrollo empresarial Loyola, 2002. (Colección Táchira Siglo XXI, n. 23).

. Las haciendas del Colegio San Francisco Xavier de la Compañía de J esús en Mérida. 1628-1767. Caracas: Universidad Católica Andrés Bello, 1985.

SAMUELSON, Robert. La imposible polarización de las sociedades occidentales. Diario La Opinión, 26 dic., 2003. n 5031. Disponible em:<http:// www.elmundo.es/ diario/ opinion/ 1550256_impresora.html>. Aceso em: 27 dez. 2003.

SCHMIDT, Peer. Una vieja elite en un nuevo marco político: El Clero Mexicano y el inicio del conservadurismo en la época de las Revoluciones Atlánticas (1776-1821). Disponible en:<www2.uni-erfurt.de/lateinamerika/ Forschung/ Colmex.pdf>.

SILVA MORENO, J osé Luis. El clero de Colima frente a la guerra de la Independencia. Estudios J aliscienses: Revista Trimestral del Colegio de J alisco, n. 74, nov., 2008.

SIMÓN, Pedro. Noticias historiales de Venezuela. Caracas: Academia Nacional de la Historia, 1963. t. 2. (Colección Fuentes para el estudio de historia colonial 67).

TAYLOR, William B. Ministros de lo sagrado. Sacerdotes y feligreses en el México del siglo XVIII. Zamora: El Colegio de Michoacán-Secretaría de Gobernación, 1999.

VILLELLAS ARIÑO, María. Hallar nuevas palabras, crear nuevo métodos. La participación de las mujeres en los procesos de paz. Madrid: Centro de Investigaciones de la Paz, 2006.

VITALE, Luis. Historia comparada de los pueblos de América Latina T. 02 Independencia y formación social republicana Siglo XIX. Procesos Históricos, n. 19, 
enero-junio, 2011. Disponible en: <www.scribd.com/ .../ Luis-Vitale-Historia-socialcomparada-de-los-pueblos-de-America-LatinaTomo-II>.

\section{Fuentes}

\section{A. Inéditas}

AAM. Sección 45B Libros Varios. Libro de órdenes y decretos superiores de los Ilustrísimos Obispos Santiago Hernández Milanés y Rafael Lasso de la Vega. Años 1807-1828. Carta pastoral del obispo Santiago Hernández y Milanés a los fieles. Carache, 18 de agosto de 1806. f. 11v-14v,

AAM. Sección 45B Libros Varios. Libro Lora-Milanés. Oficiales 1777-1812. Contestación de los canónigos del Cabildo Catedral de Mérida, Pbro. Dr. Buenaventura Arias y Pbro. Dr. Francisco Antonio Uzcátegui, a la consulta del Ilmo. Sr. Santiago Hernández Milanés, Obispo de la Diócesis de Mérida de Maracaibo, sobre la conveniencia de jurar o no la independencia de Venezuela, habida cuenta del juramento de fidelidad al Rey, presentado por el Obispo el 21 de septiembre de 1810, por ante la J unta Superior Gubernativa de la Provincia de Mérida. Mérida, 26 de agosto de 1811. p. 671-679.

AAM. Sección 54. Religiosas. Caja 12. Doc. 54-0269. Expediente para justificar las causas necesarias o evidentemente útil para el traslado perpetuo del Convento de Santa Clara de Mérida a Maracaibo. Mérida, 21 de agosto de 1816. $58 \mathrm{f}$.

AGNB. Historia Civil. T. 16. Autos sobre el socorro de la ciudad de San Antonio de Gibraltar por averla invadido el inglés [sic] y muerte del gobernador. 1666. Informe de los alcaldes ordinarios de Mérida Andrés Henríquez de Padilla y Alonso Ruiz Valero. Mérida, 18 dejulio de 1666. f. 887r-889v.

AGNB. Poblaciones T. X. Real Cédula que ordena la separación de Maracaibo de la Provincia de Venezuela y su anexión a la Provincia de Mérida. Madrid, 31 de diciembre de 1676. f. 334r-335r

AGEM. Documentos históricos de la Gobernación de Mérida 1704-1705-1711. Expediente promovido por el procurador don Cristóbal de Gámez y Costilla ante el cabildo solicitando esta se inhibiese de satisfacer los salarios impuestos. Testimonio de las autoridades eclesiásticas. Mérida, 24 de febrero de 1711. f. 1-45.

AGI. Santo Domingo. Legajo 202. Informe del procurador general de Mérida J osé García de Ambas. Mérida, 20 de abril de 1688. f 40r- 57v.

Colaboración recibida en 04/ 04/ 2010 y aprobada en 18/11/ 2010. 